\author{
INVESTIGACIONES \\ de HISTORIA ECONÓMICA \\ 2006, invierno, número 4. Pp. 101 a 138
}

\title{
Salarios y Programas de Bienestar Industrial en la empresa ferroviaria MZA (1915-1935)
}

\section{Wages and Industrial Social Welfare programmes in the railway company MZA (1915-1935)}

\author{
TOMÁS MARTÍNEZ VARA \\ Universidad Complutense de Madrid
}

\begin{abstract}
RESUMEN
Este artículo analiza la evolución de los salarios, monetarios y reales, de los empleados fijos de la compañía ferroviaria MZA durante el llamado "Problema Ferroviario". Su conocimiento resultaría muy incompleto si no se tienen en cuenta los Programas de Bienestar Industrial, pues representaron un porcentaje muy importante de las remuneraciones percibidas. Una de las principales conclusiones que se obtienen del trabajo es que, durante el período de estudio, mejoró la renta real de los ferroviarios y también se redujeron las diferencias salariales entre categorías, lo que no significa que éstas no siguieran siendo muy elevadas.
\end{abstract}

PALABRAS CLAVE: Mercado laboral, Programas de Bienestar Industrial, Salarios, Ferrocarriles españoles

Códigos JEL: J33, N14, N84, N34

\section{ABSTRACT}

We analyse in this paper the evolution of wages and salaries, in real and monetary terms, of permanent staff in the railway company MZA during the so-called "Railway Problem" period. Their understanding would not be complete without taking into account Industrial Social Welfare programmes, since these accounted for a high percentage of earnings. One of the main conclusions of this paper is that, during the period examined, the real income of railway employees improved and wage differentials between the various levels narrowed, although such levels continued to be very high.

KEYWORDS: Labour market, Industrial Welfare Programmes, Wages and Salaries, Spanish Railways

JEL Codes: J33, N14, N84, N34 


\section{Introducción ${ }^{1}$}

$\mathrm{E}$ 1 objetivo de este trabajo es muy simple. Se trata de presentar la evolución de los salarios, monetarios y reales, de los empleados fijos y de las "prácticas de bienestar industrial" llevadas a cabo por una de las dos grandes concesionarias del sector ferroviario - la Compañía de los Caminos de Hierro de Madrid a Zaragoza y Alicante (MZA) - en el período que media entre el estallido de la Gran Guerra y la crisis final de la empresa en vísperas de la Guerra Civil. Entendemos por bienestar industrial la provisión sistemática a los trabajadores, por parte de su empresa, de algún tipo de bien o servicio independiente del salario directo, aunque sea complemento fundamental de él. Se trata de prácticas inherentes a la existencia de mercados internos de trabajo sin cuyo conocimiento resulta imposible deducir, a mi juicio, el nivel de las retribuciones efectivamente percibidas por los trabajadores fijos.

El trabajo comienza (apartado primero) con una breve reflexión sobre la relación existente entre las modernas formas de gestión en las empresas ferroviarias y la formación de mercados internos de trabajo en el sector, terreno éste en el que aquéllas - como en otros - resultaron pioneras. Gracias a ellos, consiguieron reducir costes de transacción y establecer relaciones laborables más estables. Supieron, asimismo, crear complejos programas de bienestar social que acabaron por sustituir, en las fases que Tedde (1978, pp. 106-231) denomina de "afirmación" (1900-1919) e "institucionalización" (1919-1935), las antiguas relaciones laborales de corte paternalista propias de los primeros momentos. A principios del siglo XX, tanto los mercados internos de trabajo como las prácticas de bienestar social se habían extendido por todas las grandes redes europeas. Y lo mismo sucedió en España en aquellas empresas que tuvieron (apartado segundo) elevados niveles de facturación y dispusieron de sistemas de gestión profesionalizada, como eran los casos de la Compañía de los Caminos de Hierro del Norte de España (Norte) y de MZA. La documentación de esta última (apartado tercero) permite, por fortuna, valorar su alcance entre 1915 y 1935, y estimar (apartado cuarto) su contribución a los ingresos monetarios y a los niveles de vida de los trabajadores. La pregunta a la que el trabajo trata de responder, y que constituye la base del apartado quinto, es si mejoró, o no, el nivel de vida de los trabajadores en términos absolutos y con relación a los trabajadores de las demás actividades económicas, y si se amortiguaron las diferencias entre las distintas categorías durante el período de estudio; es decir, durante el llamado "problema ferroviario".

1 Este artículo tiene su origen en una comunicación presentada al III Congreso de Historia Ferroviaria, celebrado en Gijón en septiembre de 2003. Me han sido de inestimable ayuda los atinados comentarios de Cobos Arteaga, así como las sugerencias de tres exigentes evaluadores de Investigaciones de Historia Económica. Obviamente, yo soy el único responsable de los errores que el lector sin duda encontrará. 
En ambos casos — es la principal conclusión - la respuesta es positiva, lo que no quiere decir que aquéllas no siguieran siendo muy pronunciadas, ni que se deba olvidar el bajo nivel de partida de la mayoría. La construcción de un índice del coste de la vida ad hoc ha sido una herramienta de extraordinaria importancia para calibrar la evolución de las percepciones reales.

\section{Los mercados internos en las grandes ferroviarias}

La necesidad de gestionar enormes y complejos flujos en red de carga y pasajeros, para lo que se requirió gran número de trabajadores y establecimientos esparcidos por la geografía de los países, obligó a crear en las grandes compañías ferroviarias norteamericanas nuevos hábitos de gestión y contabilidad que dieron lugar al nacimiento de la empresa moderna burocratizada ${ }^{2}$. Su tamaño, complejidad y volumen de información, así como la extensión geográfica de sus actividades, las obligaron a enfrentarse a muchos problemas organizativos nuevos. Quienes dirigían estos gigantes económicos se convirtieron en el primer grupo de gerentes o ejecutivos modernos profesionalizados de Estados Unidos. Fue en ellos, pues, donde la "mano visible" de las nuevas formas de gestión empresarial apareció por primera vez $z^{3}$. Aunque con características específicas según los diferentes tamaños y estilos nacionales, también en Europa los orígenes de la empresa corporativa y de la gestión moderna estuvieron asociados al desarrollo de las grandes compañías ferroviarias ${ }^{4}$. España no constituyó ninguna excepción al respecto, aunque el predominio de una estructura empresarial de corte netamente familiar hizo que los nuevos métodos de gestión tuvieran una proyección menor ${ }^{5}$.

Por otro lado, hasta entonces ninguna otra empresa había tenido que seleccionar y dirigir un número tan elevado y diversificado de hombres (Chandler, 1965, p. 97; Lummis, 1994, p. 64), sin tener en cuenta, obviamente, los obreros empleados en la propia construcción de la red; ni se había necesitado hasta ese momento, para garantizar la seguridad de trabajadores y viajeros, disponer de normas de actividad definidas con tanta claridad ${ }^{6}$. El ferrocarril ordena la producción del transporte

\footnotetext{
2 Chandler (1987).

3 Una versión crítica en Channon (1996).

4 En el siglo XIX y el primer tercio del XX, las grandes empresas norteamericanas (Chandler, 1987) y europeas (Caron, 1973; Gourvish, 1973) eran abrumadoramente ferroviarias.

$5 \quad$ Vidal (1996).

6 En los años ochenta del siglo XIX, la Great Western Railways, una de las cuatro grandes británicas, ocupaba a más de 40.000 empleados, cifra que se elevó a 75.344 en 1919 y superó los 100.000 poco después de las fusiones de 1923 (Savage, 2000, p. 70). En 1918, la Compagnìe des Chemins de Fer du Nord, propiedad de los Rothschild, con una red ligeramente mayor que la de MZA, ocupaba a 34.556 ferroviarios; Annuaire des Chemins de Fer et des Tramways (1920).
} 
mediante la coordinación de distintos servicios, cada uno de los cuales aporta su especificidad a un complejo mecanismo técnico y humano. En los primeros momentos, la elección de personal idóneo y fiable no resultó sencilla, pues, salvo en talleres y oficinas, se trataba de profesiones en su mayoría nuevas (maquinistas, fogoneros, jefes de estación, factores, asentadores, conductores, guardafrenos, revisores, guardagujas) para cuyo ejercicio se precisaba algún tipo de cualificación que las propias compañías debían suministrar, formal o informalmente, a los candidatos seleccionados, procedentes en su mayoría del artesanado urbano, de la industria rural y del campesinado ${ }^{7}$. Para minimizar los costes asociados con el reclutamiento de la clase idónea de trabajadores y con la formación adecuada, una vez acabada la red y normalizada ya la explotación, las grandes corporaciones ferroviarias comenzaron a aplicar, desde fechas tempranas, la lógica de los mercados internos, terreno éste donde la nueva dirección empresarial también resultó pionera (Savage, 2000, p. 70). A principios del siglo $X X$, las principales ferroviarias británicas no sólo tenían establecidos mercados internos, sino que eran, según Howlett (2000), sus más firmes adeptas dentro del país. Mediante este sistema intentaban, una vez contratados los trabajadores con el perfil más adecuado, garantizar el control a través de un amplio equipo de vigilancia y, sobre todo, retener los servicios de los más estrictamente relacionados con la profesión ferroviaria; es decir, los que habían recibido de la empresa formación específica y habían acumulado más experiencia y destreza en el oficio ${ }^{8}$. De este modo, consiguieron relaciones laborales estables y seguridad frente a las incertidumbres del ciclo, se aseguraron la rentabilidad de la inversión realizada en formación $y$, mediante la identificación con la empresa, trataron de $-\mathrm{y}$ lograron- neutralizar el avance sindical, lo que era fundamental en empresas de servicios públicos muy vulnerables a los paros. En general, preferían cubrir las vacantes por medio de la promoción interna; esto es, con trabajadores eficientes, disciplinados y situados en la clasificación inmediatamente inferior dentro de la "línea de progresión", a los que, de este modo, se reconocían sus méritos, diligencia y disponibilidad o, lo que es lo mismo, su aptitud y lealtad ${ }^{9}$, siempre que cumplieran con las reglas formales diseñadas por la empresa y los candidatos reunieran las condiciones ${ }^{10}$. El esquema, aunque con cierto retraso respecto a Inglaterra y Francia, se reprodujo en España.

$7 \quad$ Kingsford (1970), pp. 1-12. Ver, asimismo, Revue d'histoire des chemins de fer (2000), 22, número dedicado al origen social y geográfico de los ferroviarios franceses.

Fitzgerald (1999), Ribeill (1998).

9 Cada compañía estableció su propio mercado interno, lo que, como indica Howlett (2000), les permitió reducir costes de transacción, planificar a largo plazo y eludir las crecientes amenazas sindicales.

10 La posibilidad de trepar por las escaleras ocupacionales indujo al empleado a permanecer en la compañía, porque su salario mejoraba con la antigüedad y porque, si la abandonaba, perdía todos los derechos laborales acumulados, aunque entrara a trabajar en otra ferroviaria. 
Pero las grandes ferroviarias, corporaciones monopolísticas intensivas en capital, retuvieron y controlaron los servicios de su "experimentada" fuerza de trabajo porque, además de "formar" mercados internos y garantizar retribuciones seguras, sus directivos supieron, también, establecer innovadores y sofisticados "programas de bienestar industrial" que acabaron por reforzar a aquéllas al generar en sus empleados conductas colaboradoras con las empresas (Fitzgerald, 1988, pp. 20-32). El trabajo seguro y bien realizado dependía, obviamente, de que cada empleado cumpliera de forma estricta con las funciones que se le habían asignado y de que estuviera a disposición de la empresa en cualquier momento del día (Lummis, 1996, pp. 6-67), lo que requería la imposición de una disciplina espartana y de una estrecha vigilancia para su cumplimiento. Pero los directivos se percataron muy pronto de que, a la hora de conseguir de los trabajadores la conducta laboral deseada, tan importante como la disciplina era disponer de un eficiente sistema de incentivos, unos orientados a complementar los salarios -casas gratuitas, pluses diversos, economato, primas varias, ayudas a familias numerosas, socorros, anticipos sin interés - y otros al establecimiento de mecanismos de prevención social —seguros de enfermedad, prestaciones médico-hospitalarias, pensiones de retiro, viudedad y orfandad-. Con dichos incentivos pretendían ganar la colaboración y lealtad de los empleados, especialmente de los más difíciles de reemplazar $^{11}$. Comenzaron siendo pequeñas prestaciones del más puro corte paternalista, que las compañías concedían gratis et amore ${ }^{12}$ y que sus directivos distribuían de manera discrecional entre los empleados cuyo historial de fidelidad y abnegación les hacía, en su opinión, acreedores a ellas, al tiempo que se convertían en un excelente instrumento frente al empuje del sindicalismo. Dado su carácter potestativo, la empresa no adquiría compromiso alguno a largo plazo y siempre podía aumentar o disminuir el nivel de la provisión en función de los ingresos y del proceder del sujeto en cuestión. Pero este tipo de prácticas de corte autoritario, paternalista y corporativo, donde la relación personal y directa entre las partes era requisito fundamental, resultó, a la larga, inapropiado en empresas tan capitalizadas y con semejante volumen de facturación y empleo. Lo que hicieron en su lugar fue regularizar el sistema, con lo que ya no cabía la discrecionalidad en las concesiones y

$11 \quad$ Fitzgerald (1988), pp. 25-32. En su excelente estudio sobre la Great Western Railway Company, Savage (1998) observó que, tras el fracaso continuado de los procedimientos de vigilancia, la dirección buscó con éxito fórmulas alternativas para fomentar conductas autorreguladoras entre los trabajadores, optando por que "trabajasen su conciencia, más que infligiéndoles castigos y multas". Ribeill (1998), pp. 402-403, lo denominó "cultura social integradora".

12 Drummond (1995), en su trabajo sobre Crew, señala que el paternalismo descansaba sobre la dialéctica entre la coerción de la compañía y el consentimiento de los trabajadores. Véanse las sugerentes reflexiones que, a propósito de este libro, hace Ackers (1998) sobre los abusos del polisémico término paternalismo. 
en su aplicación. Desde entonces, los empleados (no todos) las percibieron como derechos adquiridos en el ejercicio de su actividad continuada en la empresa y no como merced. Y, claro está, una política de bienestar normalizada -ésa es la gran diferencia entre las prácticas de corte paternalista y los "programas de bienestar industrial" (Fitzgerald, 1988, pp. 9-12) - precisaba cuantiosos ingresos para hacer frente a sus gastos, y un sistema de gestión profesionalizado que sólo la gran corporación y el modelo burocrático permitían. Supuestos ambos que en España —antes y después de la intervención del Estado en las relaciones laborales- sólo estuvieron al alcance de las dos grandes concesionarias, Norte y MZA y, en menor medida, de la Compañía de los Ferrocarriles Andaluces (Andaluces) y de la Compañía de los Caminos de Hierro de Madrid, Cáceres y Portugal (MCP).

\section{Norte y MZA: una posición hegemónica}

Aunque el primer tramo de la red se abre en 1848, la situación de España en materia de construcciones ferroviarias era, a mediados del siglo XIX, de alarmante retraso. En 1854 el número de kilómetros no superaba los 350. La aprobación de la Ley General de Ferrocarriles de 1855 cambió totalmente el panorama y supuso el inicio de un ciclo inversor expansivo en el que intervino en una proporción mayoritaria el capital exterior, lo que no debe hacer olvidar el papel decisivo también desempeñado por la ayuda estatal. El poder político condicionó, como en los demás países - en unos más que en otros-, el proceso de construcción de la red. Durante los diez primeros años, los recursos financieros y humanos movilizados fueron realmente inmensos y el número total de kilómetros construidos sobrepasó los 5.000. De las muchas compañías sobresalieron las ya citadas Norte y MZA, con un 41 por 100 del total del tendido de vía ancha. A la fase de impulso inicial siguió, sin embargo, otra de profunda crisis, no reanudándose en verdad la construcción hasta mediada la década de los setenta. Como advierte Tortella (1994, p. 109), este segundo impulso se hizo ya bajo el signo de la concentración. Norte y MZA fueron redondeando sus sistemas con la incorporación de compañías menores - algunas no tan pequeñas, como la de Madrid-Badajoz y la de Tarragona-Barcelona-Francia (TBF), adquiridas por MZA en 1878 y en 1898, respectivamente-, y completando sus redes con nuevas construcciones, la más relevante de las cuales fue la línea Valladolid-Ariza (1895), con la que MZA pretendía capturar parte del tráfico cerealista de Castilla y León. Al doblar el siglo, y una vez concluida la mayor parte de las fusiones y absorciones, cada una de las dos grandes controlaba un tercio del tendido ferroviario total, 3.552 kilómetros Norte y 3.650 MZA en 1898, una vez hubo integrado TBF. Las dos ocupaban tres cuartos del empleo del 
sector (Ballesteros y Martínez Vara, 2001). La existencia de economías de escala generó de forma natural una tendencia a la concentración de empresas y un funcionamiento cercano al régimen de monopolio. En 1917, Norte y MZA ocupaban, por la cuantía de sus activos, el primero y segundo lugar dentro del ranking empresarial español (Carreras y Tafunell, 1996). En 1921, los ingresos de Norte superaban los 287 millones de pesetas y los de MZA, los 280 millones. El tamaño de su red era similar, en ambos casos, al de la Midi francesa o al de la London $\mathcal{E}$ North-Western británica. Tal posición hegemónica dentro del negocio ferroviario español se mantuvo hasta su nacionalización en 1941, lo que no significa que sus resultados fueran satisfactorios.

Para controlar estructuras empresariales de semejante envergadura, y con una división del trabajo tan compleja, las dos grandes ferroviarias españolas adoptaron el modelo francés de gestión de empresas (Comín, Martín Aceña, Muñoz Rubio y Vidal (1998), I, p. 150), un modelo organizativo muy burocratizado, caracterizado por los principios de centralización, jerarquía, formalización y especialización ${ }^{13}$. Tal sistema constituyó un método altamente efectivo de organizar a un gran número de personas o, lo que es lo mismo, una forma muy eficiente de afrontar los requisitos administrativos de los sistemas sociales a gran escala. El reclutamiento de personal, la promoción y, en general, las reglas que definen las trayectorias laborales se configuraron de forma similar a como se hizo en las grandes redes francesas y, en general, europeas; esto es, sobre la base del mérito, la capacidad y la subordinación de los trabajadores a los objetivos de la empresa.

Por otro lado, "los programas de bienestar", al ir perdiendo desde comienzos del siglo XX su condición paternalista y autoritaria, y convertirse en derechos minuciosamente regulados - si bien en sus discursos oficiales los gerentes nunca los reconocieran como tales-, se hicieron cada vez más complejos, onerosos y difíciles de gestionar. Esto es lo que sucedió en las primeras décadas del siglo XX. Su huella en los registros contables de las empresas, empero, no siempre resulta fácil de seguir.

Para la organización de las ferroviarias galas, Ribeill (1980), pp. 29-55. La Compagnie du Nord estuvo dirigida con mano de hierro por sus directores generales, quienes, en estrecha relación con la familia Rothschild, se mantuvieron largo tiempo en el cargo. En España, este tipo de dirección lo personifica a la perfección Eduardo Maristany y Gybert. Nacido en Barcelona en 1855, era ingeniero de caminos y, como tal, trabajó en TBF, donde adquirió gran prestigio dentro de la profesión por construir el túnel de Argentera, de muy difícil ejecución, y ocupar, desde 1897, el cargo de Director Gerente. En 1908, una vez integrada TBF en MZA, fue nombrado Director General, cargo que mantuvo hasta 1934 y que le confirió todos los poderes, entre los que estaba la dirección de todos los empleados y la proposición de nombramientos y sueldos. 


\section{Fuentes e índice de precios del sector ferroviario}

En un sentido amplio, las retribuciones de los empleados en activo de "carácter fijo permanente" de MZA revestían una gran variedad de formas. Los "agentes de plantilla" percibían sueldos por mensualidades vencidas y los empleados, obreros y peones, "jornaleros asalariados" fijos, jornales por día de trabajo; ambas rúbricas constituían la parte del león del conjunto de remuneraciones. Unos y otros podían mejorar sus retribuciones mediante subidas o por ascenso a otra escala de mayor categoría. A sueldos y jornales se debía agregar un heterogéneo elenco de partidas monetarias y no monetarias (salario indirecto) - "emolumentos" u "obvenciones"- dependientes de la situación particular de cada persona. Una gran diversidad de circunstancias que provocaron enormes diferencias salariales entre trabajadores de una misma categoría laboral y que hicieron de la nómina una magnitud realmente compleja, propia de mercados muy segmentados.

Además del personal fijo, estaba el "eventual", integrado por los suplementarios con posibilidades de acceder a la plantilla cuando, "demostradas sus aptitudes", se producía alguna vacante, y los temporeros propiamente dichos, a los que no se exigía formación, ni se les reconocía plena identidad ferroviaria. Las fuentes no siempre distinguen entre ambos grupos. En cualquier caso, su remuneración dependía de las jornadas realizadas y las políticas de bienestar industrial de la empresa les resultaron siempre ajenas ${ }^{14}$. Este colectivo, con especial significación en los Servicios de Movimiento, los primeros, y Vía y Obras, los segundos, sobre todo tras la implantación de la jornada de ocho horas, representó siempre mano de obra abundante, barata y flexible que la empresa utilizó a discreción según las exigencias del momento.

Las fuentes básicas que he empleado son, por un lado, los diversos expedientes e informes puntuales que se conservan en el Archivo de la Fundación de los Ferrocarriles Españoles, particularmente los denominados Ventajas diversas de que disfruta el personal de los diferentes servicios para el año (...) ${ }^{15}$ (Ventajas, en adelante), y los referidos a los cálculos que la compañía realizó en respuesta a la pertinencia de las demandas salariales a raíz del llamado "problema ferroviario". Y, por otro, los Libros de Presupuestos (Presupuestos, en adelante) de ambas redes (Antigua y Catalana).

14 En un informe fechado en 1914, el ingeniero jefe y administrador de la red catalana, R. Coderch, exponía con toda claridad lo que pensaban los gerentes de este colectivo: "Nunca se ha creído conveniente hacer concesiones a este personal que pudiera obligarnos a hacerlo de plantilla". Archivo Histórico del Ferrocarril (AHF, en adelante), S/49/6. 
A las Ventajas ya me he referido en otra ocasión (Martínez Vara, 2004), si bien con otros propósitos ${ }^{16}$. Esta fuente ofrece información pormenorizada y fiable sobre el "número de empleados fijos" (Apéndice 1, columna 1) y el de "eventuales" por día (Apéndice 1, columna 6), la "cuantía salarial" en sentido estricto y el "gasto efectivo" que supuso a la compañía la concesión de las distintas prestaciones, así como los ingresos que, aparte de los salarios, las mismas reportaron a los trabajadores entre 1915 y 1935. La información aparece agrupada bajo tres grandes epígrafes:

1) Instituciones de carácter benéfico y de previsión establecidas a favor de su personal. Desde el punto de vista estrictamente monetario, éstas representaron muy poco, suponiendo a la empresa un desembolso nimio. De las diez rúbricas que integran el apartado (Apéndice 2a), sólo cuatro - abono de haberes en caso de enfermedad y de accidentes, gratificación a los agentes de bajo sueldo y familia numerosa y escuelas (haberes del profesorado)— incrementaban propiamente la nómina.

2) Emolumentos diversos que, aparte del sueldo, tiene asignado el personal. Comprende dieciséis rúbricas de naturaleza muy diversa (Apéndice 2b), cuyo único denominador común es la regularidad en su percepción. Estaban constituidas por las retribuciones directas por trabajos realizados - horas extraordinarias, destajos, honorarios satisfechos a profesionales especializados (al tratarse de personal no perteneciente a la plantilla, he descartado esta partida) — , abonos por descansos y licencias anuales retribuidas, indemnizaciones por alquiler de viviendas, cambio obligado de residencia o ausencia de ella, viajes, fijos y coyunturales, y primas por distintos conceptos. Lo sufragado por actos meritorios o los aguinaldos por Navidad fueron meras anécdotas contables.

3) Otras ventajas de que disfrutan los agentes de la Compañía (Apéndice 2c). Se trataba de bienes y servicios que los contables tradujeron a términos monetarios, pero que, en realidad, no significaron desembolso alguno para la empresa, ni incrementaron los salarios monetarios de los agentes. Tales son los casos de las viviendas gratuitas (en 1919, el 70,5 por 100 de los empleados disfrutaba de ellas). La empresa concedió, asimismo, billetes gratuitos a sus agentes y a los hijos de éstos que asistían a los colegios, cuya enseñanza también era gratuita; los familiares podían también viajar pagando únicamente la mitad del precio del billete. Hubo otras "ventajas de menor importancia y de imposible evaluación", como el acopio de leña de las traviesas a precios reducidos o la conducción gratuita de algunas mercancías, entre otras.

La suma de los tres conceptos (Apéndices 2a, 2b y 2c) supuso, en expresión de los contables, "el sacrificio real" que, excluidas las minas de la Reunión, le supuso a la compañía mantener todas las prestaciones. El desembolso efectivo, como ya se ha 


\section{GRÁFICO 1}

EVOLUCIÓN DE LOS SALARIOS Y DE LAS PRESTACIONES SOCIALES EN MZA, 1913-1935

(pesetas por trabajador)

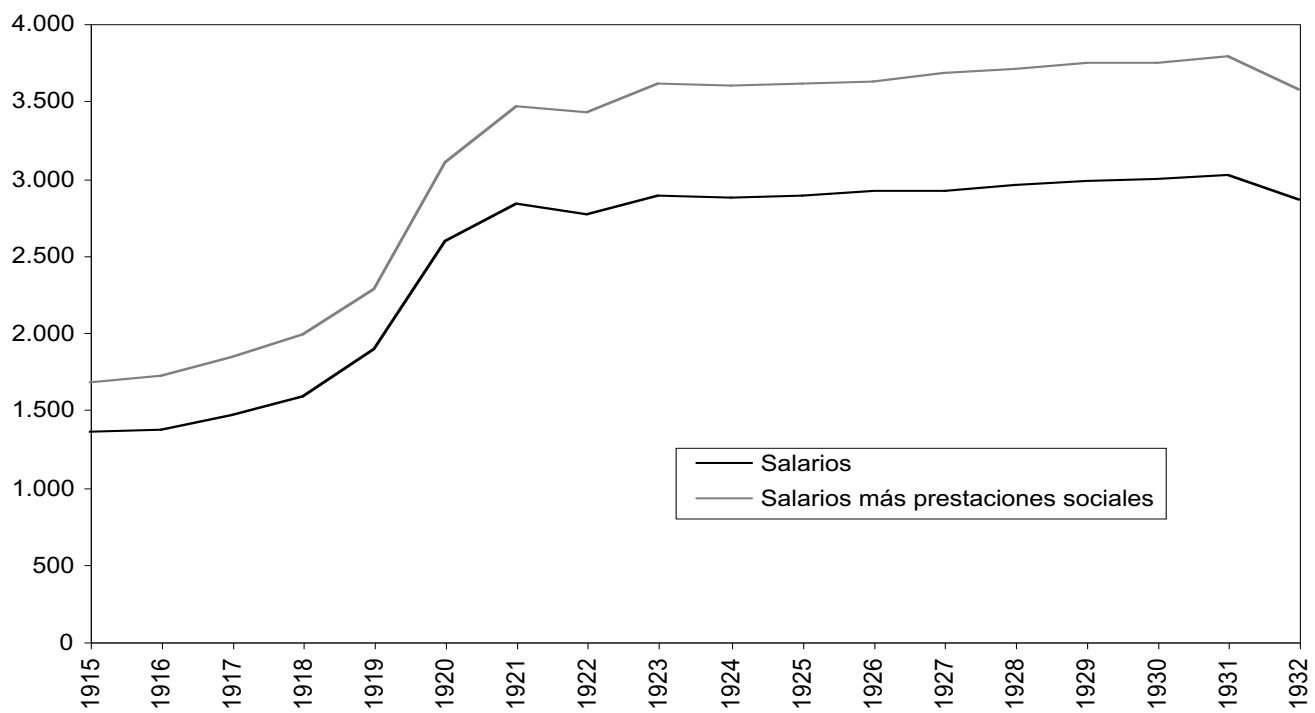

Fuentes: Apéndice 1, columnas 3 y 4.

indicado, fue menor (Apéndices $2 \mathrm{a}$ y $2 \mathrm{~b}$ ); de igual modo que lo fue lo percibido por los agentes (Apéndice 1, columna 3). En cualquier caso, y esto es lo que interesa resaltar, los ingresos monetarios adicionales representaron un porcentaje nada desdeñable de los ingresos totales percibidos por los trabajadores fijos (Gráfico 1), si bien crecieron a un ritmo ligeramente inferior: los haberes por trabajador aumentaron al 4,36 por $100 \mathrm{y}$ las prestaciones al 3 por 100. Sin el concurso de estos ingresos suplementarios se obtendría, desde luego, una visión incompleta de la situación laboral de empresa y trabajadores ${ }^{17}$. La prevención es el mejor antídoto contra el uso interesado de los datos que hacen directivos y agentes, hiperbolizándolos unos, subestimándolos los otros.

17 Refiriéndose a este asunto, la Dirección General de Trabajo y Acción Social (1927), pp. IX, XVI y CCXLIX, advertía: "La información sobre los pluses y bonificaciones que, además del salario, perciben los obreros, indispensable para elaborar una estadística de remuneraciones efectivas, resulta tan defectuosa que no puede utilizarse". Y unas páginas después: "No hemos podido (...) conseguir datos sobre las remuneraciones efectivas del trabajador, que habrían de determinarse adicionando a los salarios nominales el importe de las horas extraordinarias y demás bonificaciones". Años después, en 1931, las cosas seguían prácticamente igual. Dirección General de Trabajo y Acción Social (1931), pp. CI-CII. 
Por lo que se refiere a los Presupuestos, las directrices marcadas por el Reglamento Provisional para la Contabilidad de los Servicios de la Red Antigua, aprobado en 1908, son recogidas por primera vez en el presupuesto para 1910. Los gastos constituyen el eje central del nuevo Reglamento, que anuló todas las disposiciones anteriores no coincidentes. Su finalidad era, como reza el artículo primero, clasificar, ordenar, justificar y fiscalizar todos los gastos en los que incurriera la compañía, para realizar los pagos pertinentes y conocer los costes reales incurridos. Para desempeñar semejante cometido, con independencia de la red de que se trate - Antigua o Catalana (llevaban contabilidades independientes, excepto en los Servicios de Material y Tracción y la propia Contabilidad, centralizados en Madrid desde 1913)—, los contables debían estimar, servicio por servicio, los salarios según categorías, para determinar con el máximo rigor el gasto del año entrante; de ahí que las series resultantes muestren un retardo respecto a las de las Ventajas. Es importante - se alerta - que los "importes [del personal] sean los que realmente se han de gastar (...) en cada servicio respectivo"18. De 1915 a 1936, los Libros de Presupuestos de ambas redes incluyeron al final del análisis de cada servicio un apartado de gran interés, bajo el epígrafe "remuneración directa al personal"19, discriminando categorías (Cuadro 1, columna 4). Desafortunadamente, en dicho apartado no se contempla el empleo eventual. En cada caso, la fuente ofrece el número de agentes y los ingresos medios, desagregados en sus diversos componentes: salarios o sueldos en metálico, gratificaciones, primas, gastos de viaje, uniformes y aguinaldos (no están todas las obvenciones). Informa, igualmente, de los agentes que disfrutan de vivienda gratuita y de las horas trabajadas por agente durante el año. Aunque existen lagunas significativas (faltan en ambas redes los años 1916, 1919 y 1934, y 1925 en la catalana), la información disponible es realmente ingente. Baste con reseñar que, para cada año, la nómina de profesiones de ambas redes supera con creces el centenar. En los Apéndices 3, 4 y 5 se ofrecen datos sobre la evolución en números índice de todos los servicios de ambas redes, excepto del economato y del eléctrico, por resultar difícil homogeneizar algunas series; en todo caso, éstos representaron muy poco dentro del cómputo global. Las curvas del total de los salarios nominales (Cuadro 1, columnas 1 y 3) y la serie de remuneraciones directas de los Presupuestos (Cuadro 1, columna 4) tienen, como no podía ser de otro modo, idéntica estructura (coeficientes de correlación del 0,915 y 0,920, después de tomar logaritmos y primeras diferencias). Se distinguen, obviamente, en el nivel, según el número de prestaciones que abarque cada una; el inferior corresponde a la de los haberes y el superior a la que contiene más prestaciones, ambas procedentes de las Ventajas (Cuadro 1, columnas 1 y 3); muy próxima a esta última se sitúa la de los Presupuestos (Cuadro 1, columna 4). Operaré habitualmente con la de las Ventajas, y lo

\footnotetext{
18 AHF, Presupuestos, libro 46 (1911), pp. 3-4.

19 AHF, Presupuestos, libros 45-195 (Red Antigua) y 196-257 (Red Catalana).
} 
haré con los Presupuestos cuando interese analizar la evolución de los salarios y medir las diferencias entre categorías (Apéndices 3, 4 y 5). De las Ventajas proceden, también, las referencias al personal eventual.

Por último, si las fuentes citadas permiten disponer de una aproximación razonable a la cuantía anual del salario nominal, en uno de los expedientes que los gestores realizaron a propósito de las demandas salariales, fechado el 18 de noviembre de $1919^{20}$, se analiza el "alza del nivel de vida" y, lo que es más importante, se ofrece una estructura del gasto del personal ferroviario. Si se consideran como promedio los agentes con haberes hasta 3.000 pesetas (más del 97 por 100 del empleo), el gasto familiar se "distribuye" de la forma siguiente: alimentos 60 por 100, habitación 15 por 100, vestido 10 por 100 , combustible 7,5 por 100 y varios 7,5 por 100 . Aplicando esta estructura a los precios de la alimentación del Instituto de Reformas Sociales ${ }^{21}$ y a los del Economato, los contables rehicieron para los años de la Gran Guerra el índice de precios simple del Instituto. El resultado arrojó un nivel ligeramente más reducido. Los precios del vestido y calzado aumentaron un 75 por 100 y los de la vivienda lo hicieron un 25 por $100^{22}$. De ahí que el alza sea mayor que el que muestra el de Ballesteros (1997), al no contemplar éste subida alguna en dichas rúbricas durante estos años y ser el precio del combustible muy inferior ${ }^{23}$. Con la estructura del gasto familiar ofrecida por la propia empresa, los precios del Economato - aunque son más bajos, las fluctuaciones son las mismas - para vestido, calzado, combustible y electricidad, los de Ballesteros para alimentación y los de las Ventajas para la vivienda, he confeccionado un nuevo índice de Laspeyres con base en 1913. No presenta, desde luego, grandes discrepancias con los obtenidos por otros autores (Maluquer, 1989; Ballesteros, 1997), pero tiene la novedad - $\mathrm{y}$, en mi opinión, también la ventaja - de operar con el presupuesto familiar del grupo laboral específico al que se aplica, sin necesidad de alterar las pautas de consumo en todo el período. El resultado parece bastante verosímil (Cuadro 1, columna 5). De este modo, la respuesta a la pregunta sobre si las retribuciones en MZA subieron, $\mathrm{o}$ no, en la misma proporción que los precios encuentra una respuesta más precisa.

\footnotetext{
20 AHF, S/58/36.

21 Los boletines del Instituto de Reformas Sociales (1906-1924) ofrecían precios del petróleo, la luz eléctrica y el carbón vegetal, pero los gestores prefirieron utilizar los del Economato donde se vendían carbón, mineral y vegetal, leña de encina y artículos de vestido y calzado.

El 6 de abril de 1923 publicó Bulletin Quotidien, en su número 77, varias tablas de la subida de los precios en España entre 1914 y 1922. AHF, S/232/63, Elevación de los precios de las sustancias alimenticias y de las materias primas. Ignoro la bondad de los datos, pero, por exagerados que parezcan - los precios al por mayor de la Jefatura Superior de Estadística (1924), p. 17, son aún más elevados—, es indudable que vestido, calzado y vivienda sí subieron, como se refleja en el Economato. tar, hasta 1922, los datos del coste de la vida de la información del Boletín de Estadística de la Dirección del Instituto Geográfico, Catastral y de Estadística (37, 38, 39 y 40, p. 12) y los datos de 1931/33 del Boletín del Ministerio de Trabajo, Sanidad y Previsión Social (1924-1936). MZA (1934).
} 


\section{Los salarios de los trabajadores de MZA: interrogantes y respuestas}

Tanto los gerentes de Norte, como los de MZA, consideraron siempre que sus empleados, además de disponer de empleo seguro - lo que era cierto en el caso de los agentes de plantilla- y de tener remuneraciones superiores a las de la mayoría de los sectores económicos del país — lo que debe ser matizado-, disfrutaban, además, de beneficios sociales desconocidos en otras empresas - lo cual también requiere matizaciones-. La conclusión, obviamente, no podía ser otra: sus empleados disfrutaban de un nivel de vida por encima del resto de los trabajadores, empleados de otras industrias y funcionarios, siendo un grupo privilegiado dentro del mundo laboral ${ }^{24}$. Por ello, les costaba entender sus demandas $y$, sobre todo, la actitud rígida con la que, a veces, se les exigía una respuesta inmediata.

En cuanto al índice del coste de la vida, el comienzo de la Gran Guerra supone la ruptura con el período anterior de relativa estabilidad (Ballesteros, 1997) y marca el inicio de la espiral alcista provocada por el conflicto. La escalada tiene su momento álgido en 1918, con una tasa de crecimiento en ese año superior al 18 por 100; el nivel máximo se produjo, sin embargo, en 1920, año a partir del que, tras un breve período de reajuste, el nivel permanece elevado, si bien con una ligera tendencia decreciente, salpicada por fluctuaciones menores. Los salarios monetarios respondieron con un retraso considerable a las tensiones inflacionarias. En 1916, los agentes, liderados por las organizaciones sindicales, se quejaban amargamente de la caída del poder adquisitivo de sus remuneraciones y amenazaron con movilizarse -en Norte se llegó, incluso, a la huelga (Plaza, 2004, pp. 454490)- Les asistía toda la razón, pues sus ingresos se habían deteriorado más de 12 puntos desde 1914. Un aspecto que no se tratará aquí es si los incrementos salariales se justificaban, o no, con el aumento de la productividad ${ }^{25}$. La compañía, forzada por la presión obrera, acabó reconociendo la situación y concedió una primera gratificación extraordinaria, equivalente al 8,3 por 100 de los salarios percibidos en 1914, aunque no era extensible a todo el personal (quedaron excluidos los que ya disfrutaban de otra especial). Naturalmente, la subida fue considerada insuficiente. Aunque la empresa hubo de conceder otras dos gratificaciones más, una en 1917 y otra en 1918, el quebranto en este último año se situó en 23,75 puntos. En este contexto debe entenderse el deterioro de las relaciones con sus empleados y la conflictividad subsiguiente.

24 Gaceta de los Caminos de Hierro, 1 de enero de 1917 y 1 del agosto de 1918; Unión Nacional Económica (1934), pp. 122, 125 y 134-135.

25 Véase Martínez Vara (2005). 


\section{CUADRO 1}

SALARIOS NOMINALES Y REALES E ÍNDICE DE PRECIOS

DE LOS TRABAJADORES FIJOS DE MZA, 1913-1935

(pesetas, base $100=1913$ )

\begin{tabular}{|c|c|c|c|c|c|c|}
\hline \multirow{2}{*}{ Años } & \multicolumn{3}{|c|}{$\begin{array}{c}\text { Salarios nominales } \\
\text { (Ventajas) }\end{array}$} & \multirow{2}{*}{$\begin{array}{c}\text { Salarios } \\
\text { Presupuestos * } \\
\text { (4) }\end{array}$} & \multirow{2}{*}{$\begin{array}{l}\text { IPC } \\
(5)\end{array}$} & \multirow{2}{*}{$\begin{array}{c}\text { Salarios reales } \\
\text { (Ventajas) } \\
6=(3 / 5) \times 100\end{array}$} \\
\hline & $\begin{array}{c}\text { Salarios } \\
\text { (1) }\end{array}$ & $\begin{array}{c}\text { Obvenciones } \\
\text { (2) }\end{array}$ & $\begin{array}{c}\text { Total } \\
(3)=(1)+(2)\end{array}$ & & & \\
\hline 1913 & 1.341 & 326 & 1.667 & 1.370 & 100,00 & 100,00 \\
\hline 1914 & 1.339 & 326 & 1.665 & 1.411 & 106,11 & 94,62 \\
\hline 1915 & 1.354 & 326 & 1.680 & 1.443 & 113,66 & 88,72 \\
\hline 1916 & 1.364 & 353 & 1.718 & 1.514 & 116,22 & 88,09 \\
\hline 1917 & 1.464 & 376 & 1.841 & 1.558 & 129,53 & 85,82 \\
\hline 1918 & 1.580 & 404 & 1.984 & 1.659 & 156,40 & 76,15 \\
\hline 1919 & 1.890 & 398 & 2.288 & 1.914 & 177,50 & 77,37 \\
\hline 1920 & 2.586 & 519 & 3.106 & 3.122 & 200,97 & 92,75 \\
\hline 1921 & 2.829 & 632 & 3.462 & 3.272 & 182,39 & 113,91 \\
\hline 1922 & 2.762 & 661 & 3.423 & 3.358 & 182,47 & 112,61 \\
\hline 1923 & 2.888 & 719 & 3.607 & 3.295 & 173,71 & 124,63 \\
\hline 1924 & 2.871 & 726 & 3.597 & 3.317 & 189,61 & 113,86 \\
\hline 1925 & 2.883 & 728 & 3.612 & 3.349 & 189,57 & 114,35 \\
\hline 1926 & 2.907 & 722 & 3.630 & 3.337 & 177,55 & 122,70 \\
\hline 1927 & 2.915 & 756 & 3.672 & 3.332 & 180,33 & 122,16 \\
\hline 1928 & 2.948 & 754 & 3.702 & 3.372 & 173,66 & 127,96 \\
\hline 1929 & 2.976 & 761 & 3.738 & 3.394 & 173,55 & 129,49 \\
\hline 1930 & 2.987 & 758 & 3.745 & 3.405 & 173,01 & 129,93 \\
\hline 1931 & 3.015 & 757 & 3.773 & 3.466 & 183,54 & 123,37 \\
\hline 1932 & 2.860 & 707 & 3.568 & - & 179,18 & 119,51 \\
\hline 1933 & 2.886 & 779 & 3.666 & - & 171,95 & 127,95 \\
\hline 1934 & 2.865 & 771 & 3.637 & - & 176,62 & 123,58 \\
\hline 1935 & 2.787 & 766 & 3.553 & - & 172,06 & 123,95 \\
\hline
\end{tabular}

* He decidido prescindir de los últimos cuatro años por ser la información muy fragmentaria.

Fuentes: Columnas 1 y 2: AHF, S/53/33: 1915-1921; S/54/34: 1922-1930; S/55/45: 1931-1932; MZA (1933 y 1935). Columna 4: Presupuestos, Libros 45-257. 
La situación económica de la empresa, no obstante, era muy complicada. El incremento de los salarios vino precedido, desde agosto de 1914, de una subida aún mayor de los precios del carbón y de las materias necesarias para la explotación, cuya incidencia fue extremadamente acusada. Para los gerentes la única solución posible pasaba porque el Estado revisara al alza las tarifas, de modo que cubrieran los gastos de explotación, las cargas financieras y una remuneración "razonable" del capital. Argumentaban que, si no se hacía así, las empresas, debido a la falta de capital, no podrían renovar equipos e instalaciones, ni retribuir dignamente al personal. Al fin, aunque con la oposición de prácticamente toda la sociedad (cámaras de comercio, círculos mercantiles, asociaciones de agricultores y ganaderos), el 26 de diciembre de 1918 fue autorizado un recargo máximo del 15 por 100 sobre las tarifas vigentes ${ }^{26}$. No era lo que las concesionarias deseaban, pero ello les iba a permitir afrontar los nuevos incrementos salariales. Éstos consistieron en la concesión, para todos los agentes fijos, de una gratificación equivalente al importe de dos mensualidades, y de un plus extraordinario que osciló entre el 20 y el 35 por 100 de los haberes de 1914, aplicado en razón inversa a la importancia de los mismos. Aún así, los salarios siguieron estando por debajo de los precios, por lo que las reivindicaciones continuaron.

La "política de economías" que los gestores trataron de implementar tropezó, además, con otro obstáculo: la implantación de la jornada de ocho horas. La medida debía entrar en vigor el 1 de octubre de ese mismo año en unos casos y a partir de 1920 en otros. Esto trajo consigo un aumento inmediato del salario/hora y una caída de la productividad por empleado en los servicios donde se implantó. Las concesionarias solicitaron del gobierno una nueva elevación de las tarifas. No lo consiguieron, pero sí obtuvieron los denominados "anticipos". El gobierno decidió adelantar a las compañías, con carácter reintegrable y sin interés, las cantidades a que ascendiera la nueva mejora de los haberes ${ }^{27}$. Para MZA supuso un balón de oxígeno transitorio pues, de no haber sido por estos ingresos adicionales, hubiera incurrido en pérdidas entre 1920 y 1923. Con cargo a este concepto, y desde marzo de 1920, se concedió al personal un segundo plus sobre el haber antiguo que se añadía al de 1919; se mantenía, por otro lado, la gratificación general equivalente a una mensualidad, pero calculada ahora sobre los nuevos haberes ${ }^{28}$. El plus extraordinario y el anticipo desaparecieron para integrarse dentro de los haberes ordinarios a

26 La subida, en realidad, resultó bastante mayor para el transporte de mercancías, pues gran parte de las tarifas especiales fueron suprimidas.

27 Se otorgaron por Real Orden de 23 de marzo de 1920, confirmada por la del 10 de abril siguiente, y desaparecieron en 1926. Fueron pagados directamente desde el Presupuesto. Comín, Martín Aceña, Muñoz Rubio y Vidal (1998), I, p. 306.

$28 \quad$ MZA (1934), pp. 11-14. 
partir de 1927. Sumados todos los conceptos, el incremento con respecto a 1913 osciló entre un máximo del 133 por 100 y un mínimo de 75 por 100. Un caso excepcional lo constituyó el personal de categoría superior, que percibió la gratificación especial, pero no la mensualidad adicional; en su caso el incremento fluctuó entre el 35 y el 60 por 100 .

Al fin, los salarios acabaron ganando la carrera a los precios; en los años siguientes, los ferroviarios no sólo consiguieron recuperar el poder adquisitivo perdido durante el ciclo bélico, sino que lo mejoraron ostensiblemente ${ }^{29}$. Es el mismo proceso que describen Maluquer (1989) para la industria textil catalana, Fernández de Pinedo (1992) para Altos Hornos, Escudero (2001) para las minas de Vizcaya, Sancho (2004) en el caso de la fundición Averly de Zaragoza y, a nivel general, Vilar (2004). La semejanza con la evolución del sector del transporte no debe sorprender según atestigua la Dirección General del Trabajo (1931, Cuadro XVII). Las recriminaciones de los gerentes a la abusiva política social de la República, explicables por la crisis que atravesaban, tanto el país como las propias concesionarias, y el peso creciente de los sindicatos, no se ven, sin embargo, reflejadas - lo propio sucede en la industria textil catalana (Llonch, 2004, pp. 120-121) - en la curva de salarios reales de esos años (Cuadro 1, columna 6), lo que es coherente con el magro incremento logrado por los agentes en esos años. Las mejoras más relevantes en el período recayeron en el personal eventual. Aunque la información cuantitativa seriada es posterior a la Gran Guerra, todo parece indicar que este colectivo, sin capacidad de presión alguna, fue el más castigado por la espiral inflacionista, no consiguiendo recuperar el nivel adquisitivo de 1913 hasta 1928 y ganando sólo un 26 por 100 entre este año y $1935^{30}$.

¿Deben estimarse exageradas las consideraciones neo-hobbesianas de los gerentes de MZA, y de otras concesionarias, sobre el nivel salarial demasiado elevado de sus empleados tras las mejoras posbélicas? ¿Se trató simplemente de una expresión, algo más retórica de lo normal, del pesimismo generalizado que marcó las opiniones de los gerentes sobre el "problema ferroviario"? Los resultados de la explotación, ¿habrían permitido a las empresas una política social diferente?

29 De acuerdo con la Dirección General de Trabajo (1931), p. CLX, los obreros más favorecidos entre 1913 y 1930 fueron, en términos reales, los ferroviarios, que ganaron un 19 por 100.

30 Se ha realizado el cálculo dividiendo el importe de los haberes del personal suplementario y jornalero por el "número medio de agentes por día para el conjunto del año" (Apéndice 1, columnas 6 y 7), lo que no presupone que los individuos fuesen los mismos todos los días. 


\section{Convergencia dentro de la disparidad}

En el mentado opúsculo Situación del personal en la Compañía (MZA, 1934) se hacía hincapié en tres aspectos fundamentales que, a juicio de sus autores, diferenciaban el empleo ferroviario del resto: "continuidad y seguridad en la remuneración", devengo del jornal o sueldo del agente "todos los días del año" y, por último, derecho a prestaciones complementarias sin "paridad en la masa obrera calificada del país" (en los dos primeros casos la cursiva es del original, en el último es mía). Líneas más adelante, los autores confrontan el nivel de vida del obrero especializado en otros ramos industriales con el de los ferroviarios, en general, y con los de MZA en particular. Después de tomar como base la información publicada por la Dirección General de Trabajo en 1927 y 1931 - Estadísticas de Salarios (1914-1930) — , cotejan los datos utilizando tres variables: fluctuaciones del salario nominal, evolución del coste de la vida y, como resultado de la combinación de ambas, variaciones del salario real. La primera es el resultado de dividir el salario monetario semanal por el número de horas ordinarias de trabajo (9 en 1914 y 8 para el resto de las fechas reseñadas) ${ }^{31}$. Para el cálculo del índice de precios hicieron uso de la información de los Boletines del Instituto de Reformas Sociales (1909-1924), continuada hasta 1930 por el propio Ministerio de Trabajo.

Los resultados (Cuadro 2) sólo tienen un valor muy relativo. Sin negarles el carácter "oficial y objetivo" que le otorgaba la revista Ferrocarriles y Tranvías (octubre de 1931), la propia Dirección General de Trabajo advertía, con toda razón, de la existencia de muchas "inexactitudes e incongruencias" en el asunto de las horas contabilizadas (1927, p. XVI) y de la falta de datos indispensables, como bonificaciones y prestaciones sociales (1931, p. CI). Por otro lado, el opúsculo sí especifica que la estadística de MZA comprende todo el personal catalogado como inferior - lo que es cierto $^{32}$ - , pero deja en blanco la casilla de los ferroviarios concerniente a los salarios semanales de 1920, año, por lo demás, básico; tampoco aclara si estos últimos comprenden, o no, otros ingresos informales, y además es erróneo el índice de los salarios reales de MZA de 1930 (he utilizado su mismo deflactor y el resultado es 128,3 y no 141,0, cifra más acorde con la de la columna 6 del Cuadro 1). En cualquier caso, y aunque el opúsculo adolece de todos los defectos propios de los folletos propagandísticos, es claro que, en términos generales, el nivel medio de las remuneraciones de los

31 El tiempo medio de trabajo por día de trabajo, medido en horas en 1914, se corresponde poco con la realidad. Hay que distinguir entre presencia en el trabajo y trabajo efectivo. Por lo que se refiere al primer grupo, sólo disfrutaban de jornada de 9 horas, o menos, el personal de oficinas. La nueva jornada laboral comenzó en 1920, pero no se acabará de imponer totalmente hasta los años treinta, cuando se extienda a todo el personal de las "guarderías".

32 He cotejado los salarios semanales de esta fuente con los de las "remuneraciones directas" de los Presupuestos y las diferencias son nimias. 


\section{CUADRO 2}

SALARIOS MEDIOS SEMANALES E ÍNDICES DE SALARIOS REALES, 1914-1930

\begin{tabular}{|c|c|c|c|c|c|c|c|c|}
\hline \multirow[t]{2}{*}{ Grupos } & \multicolumn{4}{|c|}{$\begin{array}{c}\text { Salarios semanales medios } \\
\text { efectivos (pesetas) }\end{array}$} & \multicolumn{4}{|c|}{$\begin{array}{l}\text { Índices de salarios reales } \\
\qquad 1914=100\end{array}$} \\
\hline & 1914 & 1920 & 1925 & 1930 & 1914 & 1920 & 1925 & 1930 \\
\hline Obreros calificados & 24,9 & 38,9 & 49,3 & 44,1 & 100 & 79,2 & 106,6 & 103,8 \\
\hline Ferroviarios en general & 24,0 & $42,6^{*}$ & 45,0 & 49,9 & 100 & $89,3^{*}$ & 106,0 & 119,0 \\
\hline Red de MZA & 27,0 & 62,1 & 64,1 & 65,5 & 100 & 117,0 & 127,0 & $128,0^{*}$ \\
\hline
\end{tabular}

agentes fijos en MZA, como en Norte, era relativamente elevado y mejoró de forma ostensible respecto al de otros empleados a lo largo del período ${ }^{33}$. La misma idea se infiere de la comparación de mis datos con los proporcionados por Soto Carmona (1992) para la misma empresa y para otras industrias y servicios. Así pues, durante todo el período los salarios monetarios de los trabajadores de MZA se fueron situando entre los más elevados, con y sin emolumentos.

Pero los gerentes también quisieron dejar muy claro en sus múltiples informes que, desde 1913, las diferencias salariales internas de la compañía se fueron acortando y estaban, desde luego, muy lejos de ser las que —en su opinión - realzaban hasta la deformación los sindicatos, particularmente el Sindicato Nacional Ferroviario. El crecimiento de las remuneraciones de 1915 a 1921 — ya se ha dicho— fue más vivo en las categorías inferiores, lo que se ve ratificado por el marcado descenso del índice Gini confeccionado con la información de los Presupuestos de la Red Antigua (Gráfico 2) en esos años. Además, como entre 1921 y 1930 no existieron apenas alteraciones de importancia (Dirección General del Trabajo, 1931, p. XCII) al margen de los efectos de los ascensos, el índice muestra una gran estabilidad con una muy tenue inclinación a la baja, baja que probablemente - las lagunas impiden verlo con claridad - debió de acentuarse durante la II República, ya que los incrementos salariales, aunque muy exiguos, afectaron únicamente a los estratos más humildes. A ello no fueron ajenos el creciente peso de los sindicatos, la implantación de la negociación colectiva y, al final, la regulación salarial. 


\section{GRÁFICO 2}

EVOLUCIÓN DEL ÍNDICE DE GINI (RED ANTIGUA), 1913-1932

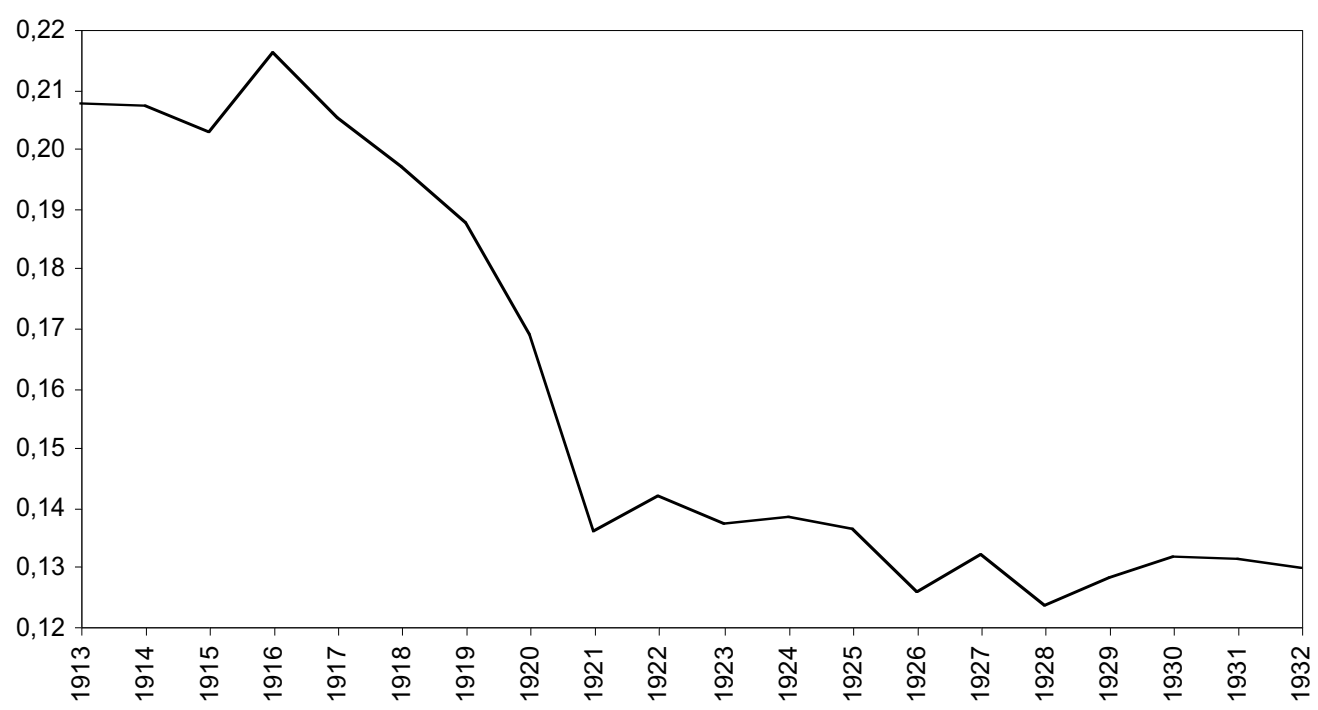

Fuentes: AHF, Presupuestos, Libros 45-195.

Pero que la distribución de la renta salarial tendiese a ser más igualitaria no significa que no persistieran profundas desigualdades. Éstas continuaron siendo muy pronunciadas, tanto en lo relativo a categorías y antigüedad, como a la diferencia de sexo. Las profesiones más favorecidas fueron las de "cuello blanco", cualquiera que fuera el servicio del que se tratase. Sus funciones básicas consistían en planificar, gestionar y coordinar la empresa. A quienes las ejercían, se les exigía haber superado previamente determinados procesos de educación formal. Aunque los hubo en todos los servicios, fueron mayoría en los de Dirección General, Secretaría del Consejo de Administración, Contabilidad General, Sanidad, Contencioso e Intervención y Estadística, donde convivían desde la Dirección y Gestión hasta trabajadores empleados en tareas burocráticas y ordenanzas. Eran, obviamente, los mejor remunerados y los que gozaban de mejores condiciones laborales. Pese a las enormes diferencias dentro de los propios servicios, la media de los ingresos por trabajador estable se situó (Gráfico 3) muy por encima de la general, especialmente en las funciones directivas (Dirección General y Secretaria del Consejo). Sin embargo, excepto los Servicios de Intervención y Estadística, que ganan poder adquisitivo, y Sanidad, que sigue el mismo ritmo de subida que los precios, en los demás servicios los salarios reales experimentan tasas de crecimiento inferiores al resto, lo que es coherente con lo que apunta el índice de Gini. 


\section{GRÁFICO 3}

EVOLUCIÓN DE LOS SALARIOS MEDIOS DE LOS EMPLEADOS EN LOS SERVICIOS INDICADOS, 1913-1933

(pesetas)

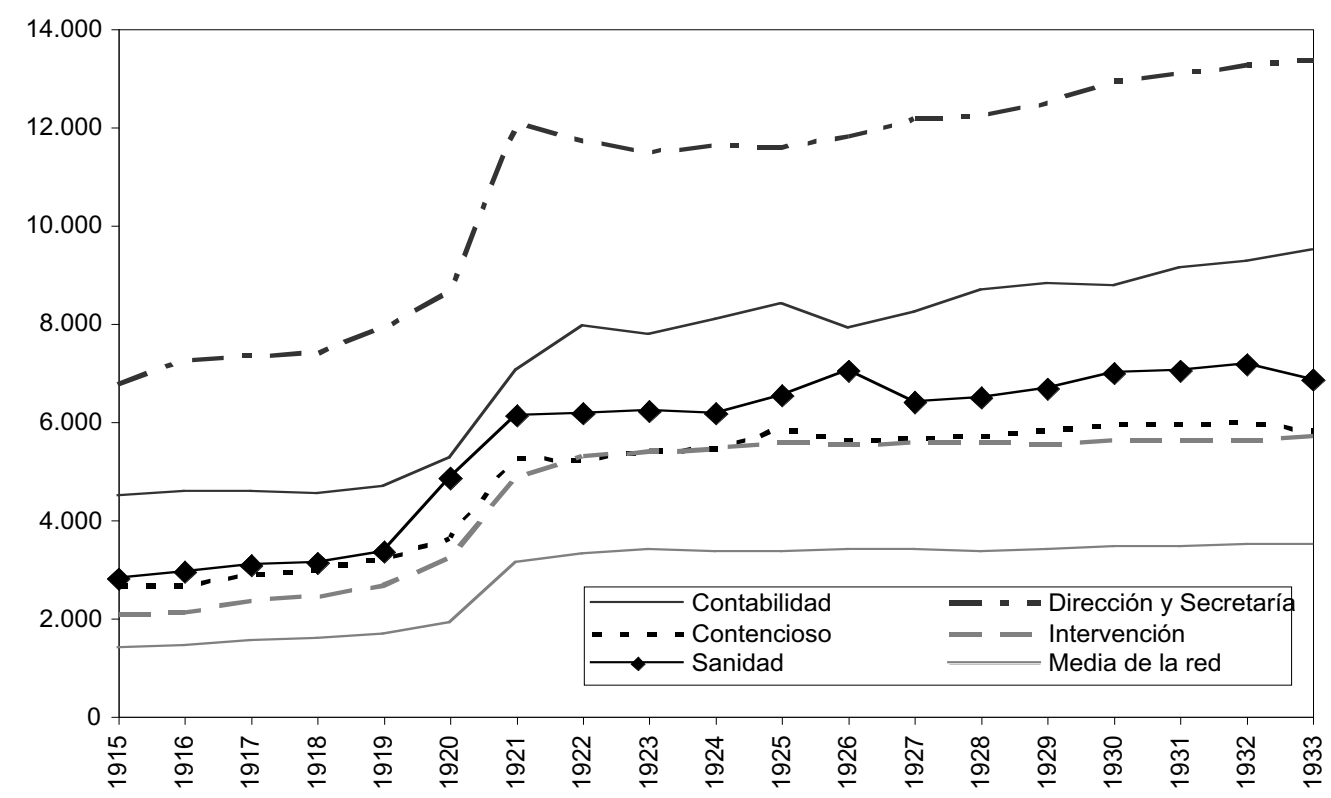

Fuentes: AHF, Presupuestos, Libros 45-195. Apéndices 4 y 5.

En el extremo opuesto estaba el personal inferior de las estaciones en el Servicio de Movimiento y el encargado de la conservación de la vía (brigadas) y la vigilancia de los pasos a nivel (guardabarreras) en el de Vía y Obras. Salvo la estabilidad, las demás condiciones se ajustan al tipo de empleo secundario. En el primer caso se trataba de un colectivo muy numeroso y heterogéneo (enganchadores, guardagujas, telegrafistas, mozos, porteros, ordenanzas, guardabarreras, escopeteros). En conjunto, su remuneración se situó durante todo el período entre el 20 y el 22 por 100 por debajo de la media general en la Red Antigua y algo menos sobre toda la red (Gráfico 4); en términos reales, recortaron al final algunos puntos, pero siguieron muy atrás.

Peor aún fue la situación, como se puede apreciar en el Gráfico 4, de los mencionados trabajadores del Servicio de Vía y Obras, el segmento inferior de la estructura laboral junto con el empleo eventual. Los obreros de las brigadas, organizadas por tramos de vía a cargo de un capataz, y éste de un asentador, percibieron, hasta 1931, en torno al 30 por 100 menos de la media general de la Red Antigua, los guardabarreras 


\section{GRÁFICO 4}

EVOLUCIÓN DE LOS SALARIOS MEDIOS DE LOS OFICIOS RELACIONADOS, 1915-1932

(pesetas)

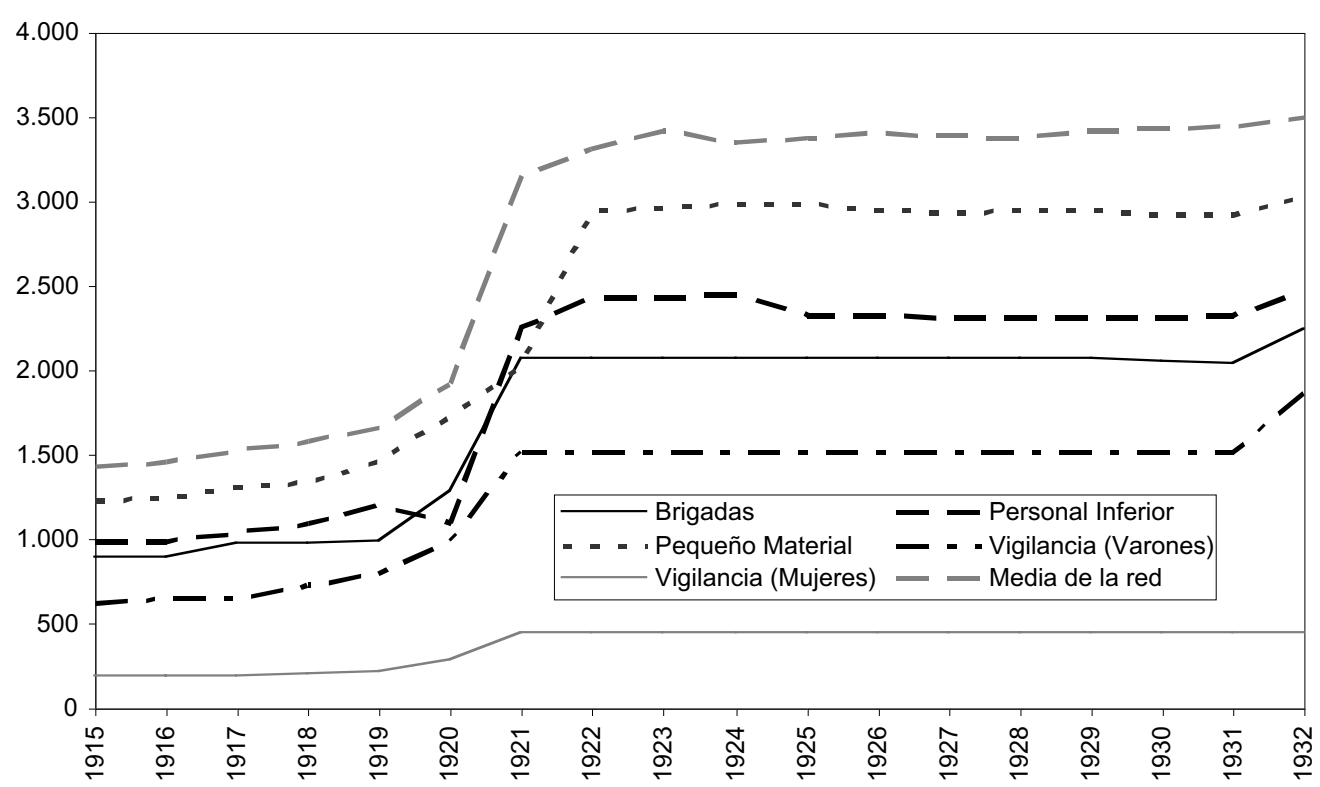

Fuentes: AHF, Presupuestos, Libros 45-195.

varones entre el 48 y el 50 por 100, y las guardesas aún menos ${ }^{34}$. Los gobiernos de la República mejoraron de forma apreciable su situación -impusieron la nueva jornada laboral en las "guarderías" e incrementaron sus magras remuneraciones-, pero aún así, los brigadistas, que en 1934 habían ganado 51 puntos en términos reales respecto a 1913, seguían percibiendo casi un 13 por 100 menos que la media de toda la red, y lo propio ocurría con los guardabarreras y las guardesas que, aun habiendo ganado 87 y 55 puntos, respectivamente, siguieron un 20 y un 80 por 100 por debajo de la media (Apéndice 3d). Con este nivel salarial, ¿cubrían sus perceptores el presupuesto familiar? Es difícil creer que así fuera; entonces, ¿cómo resolvían la situación de precariedad? Con la mesura obligada por la escasa información, la respuesta, o al menos una parte de ella, reside en prácticas de economía sumergida.

34 Según la información proporcionada por la Dirección General de Trabajo y Acción Social (1927), p. XXII, Cuadro XXXIX, eran las que menos ganaban entre la población asalariada femenina. 
Entre el segmento superior y el inferior se sitúa un conjunto muy variado de profesiones para las que se requiere una cualificación específica, lograda in situ y determinada por el tipo de empleo y categoría a desempeñar (maquinistas y fogoneros en Material y Tracción, jefes de estación, factores, revisores, conductores e inspectores en Movimiento) y que disfrutan de condiciones laborales de excepción entre los trabajadores manuales de la España de la época: estabilidad en el empleo, nivel de ingresos más o menos digno, promoción interna perfectamente reglada y acceso al salario indirecto y a prestaciones sociales. El servicio que mejor sintetiza estos caracteres es el de Material y Tracción, donde tan sólo los obreros de los recorridos percibían ingresos inferiores a la media general. Si el promedio de la red catalana se sitúa por debajo del general se debe a que este servicio se hallaba centralizado en Madrid. Por otro lado, su "puerto de entrada" tenía mucho que ver con lazos de parentesco, pues se les daba preferencia en cualquiera de las pruebas de acceso. En la profesión de ferroviario la endogamia fue siempre una constante.

\section{Reflexión final}

Las grandes ferroviarias españolas, como sus homólogas de Europa, tenían establecidos, a principios del siglo XX, sistemas de mercados internos - empleo estable, determinadas carreras de promoción y procedimientos formales para regular las relaciones laborales - y, ligados a ellos, programas de bienestar industrial cuya magnitud y complejidad en el caso de MZA han quedado de manifiesto en estas páginas. La generalización de éstos implicó para la compañía contar con mano de obra bien formada, estable, eficiente, leal y barata, pero también supuso un notable incremento de los gastos de personal, dentro de un mercado rígido cuando más necesitaba ajustar plantillas y reducir los costes de explotación. Para los ferroviarios, por su parte, implicó un plus adicional en los ingresos, al que se añadió la provisión gratuita de ciertos bienes, servicios e instituciones que suplieron las insuficiencias de la política social del Estado.

No cabe duda de que, o por los incrementos de las remuneraciones, o debido a la política de ascensos, los empleados fijos mejoraron sus ingresos reales en el transcurso del período analizado. Pero no se debe olvidar, sin embargo, que para la mayoría el nivel de partida fue bajo y, en muchas profesiones, muy bajo, y que, como consecuencia de la gestión laboral de la empresa, las desigualdades eran, asimismo, gigantescas, y lo siguieron siendo, si bien ligeramente atenuadas. Eran demasiados los intereses que contribuían a mantener la fuerte segmentación del mercado laboral ferroviario. 
La empresa utilizó a los eventuales como mero "colchón" frente a los avatares de la coyuntura. Ciertamente su empleo varió en el mismo sentido que la demanda de transporte, pero lo que más incidió fue la implantación de la nueva jornada laboral y, al final del período, la necesidad de economizar recursos. También los salarios reales de este colectivo mejoraron respecto a 1913, si bien para ello hubieron de esperar hasta la II República. Aún así, siguieron siendo muy bajos.

¿Hasta qué punto mejoró la calidad de vida de los trabajadores durante este período? La cuestión es demasiado compleja y no soy tan pretenciosos como para creer que he dado con la respuesta. Lo que sí ha quedado claro en estas páginas es que los agentes, fijos y eventuales, vieron aumentar su renta real y, también, en el primer caso, mejorar las prestaciones recibidas, dos indicadores inequívocos que, con todos los reparos que se quiera, significan un grado mayor de bienestar, por encima de otros muchos sectores de la actividad económica, lo que no quiere decir que éste fuera el idóneo, ni que se extendiese por igual a todas las categorías. Calificar de privilegiados a los agentes de Norte y MZA por el mero hecho de disfrutar de empleo fijo, sin hacer distinciones, ni conocer la esperanza de vida o el nivel de siniestralidad, por sólo citar alguna de las variables que están esperando su análisis, supone situar en esa categoría a mozos, brigadas o guardesas, lo que no tiene nada que ver con la realidad, aunque sí sirve para que se mantenga el tópico.

Para terminar, hago mías las palabras de Ferner y Fina (1988, p. 133) en su estudio de los salarios de RENFE durante el franquismo: "Como toda la información procedente de 'estudios de casos' (...) debe ser tratada con sumo cuidado a la hora de extraer conclusiones que se quieran aplicar a un ámbito más amplio [en este caso, toda la red ferroviaria] que aquél en el que ha sido generado".

\section{Bibliografía}

ACKERS, Peter (1998): “On Paternalism: Seven Observations on the Uses and Abuses of the Concept in Industrial Relations, Past and Present", Historical Studies in Industrial Relations, 5, pp.173-193.

BALLESTEROS, Esmeralda (1997): “Una estimación del coste de la vida en España”, Revista de Historia Económica, 2, pp. 363-395.

BALLESTEROS, Esmeralda, y MARTINEZ VARA, Tomás (2001): “La evolución del empleo en el sector ferroviario español, 1893-1935", Revista de Historia Económica, 3, pp. 636-678.

BARTHE et BARTHE, André (1896): Le salaire des ouvriers en Espagne, Madrid, Imp. Richard Fé. 
CARON, François (1973): Histoire de l'explotation d'un grand réseau. La compagnie de chemin de fer du Nord, París, École Pratique de Haute Études.

CARRERAS, Albert, y TAFUNELL, Xavier (1996): “La gran empresa en la España contemporánea: entre el Mercado y el Estado", en COMÍN, Francisco, y MARTIN ACEÑA, Pablo (eds.), La Empresa en la Historia de España, Madrid, Civitas, pp. 73-92.

CHANDLER, Alfred D. (1965): The Railroads. The Nation's First Big Business. Sources and Readings, New York, Cork, Harcour, Brace \& World.

-(1987, [1977]): La mano visible. La revolución en la empresa norteamericana, Madrid, Ministerio de Trabajo y Seguridad Social.

CHANNON, Geoffrey (1996): “A. D. Chandler's "visible hand" in transport history: a review article", en GOURVISH, Terry (ed.), Railways I. Studies in Transport History, Hants, Scholar Press, pp. 153-164.

COMÍN, Francisco, MARTIN ACEÑA, Pablo, MUÑOZ RUBIO, Miguel y VIDAL OLIVARES, Javier (1998): 150 Años de Historia de los Ferrocarriles en España, Madrid, Anaya.

DIRECCION GENERAL DE TRABAJO (1931): Estadística de Salarios y Jornada de Trabajo, referidas al período 1914-1930, Madrid, Imprenta de los Sobrinos de la Sucesora de M. Minuesa de los Ríos.

DIRECCIÓN GENERAL DE TRABAJO Y ACCIÓN SOCIAL (1927): Estadística de Salarios y Jornada de Trabajo, referidas al período 1914-1925, Madrid, Imprenta de los Sobrinos de Sucesora de M. Minuesa de los Ríos.

DRUMMOND, Dianne K. (1995): Crew: Railway Town, Company, and People, 18401914, Aldershot, Scholar Press.

ESCUDERO, Antonio (2001): “Mercado de trabajo, salarios y distribución de la renta en las minas de Vizcaya (1876-1936)", en ARENAS, Carlos, PUNTAS, Florencio, y PONS, Jerònia (eds.), Trabajo y relaciones laborales en la España Contemporánea, Sevilla, Mengablum.

FERNÁNDEZ DE PINEDO, Emiliano (1992): “Beneficios, salarios y nivel de vida de los obreros en una gran empresa siderúrgica vasca, Altos Hornos de Vizcaya (1902-1927). Una primera aproximación", Revista de Historia Industrial, 1, pp. 125-195.

FERNER, Anthony, y FINA, Lluis (1988): “La dinámica salarial durante el Franquismo. El caso de RENFE”, Revista de Historia Económica, VI, 1, pp. 131-161.

FITZGERALD, Robert (1988): British labour Management and Industrial Welfare, 18461939, London, Groom Helm.

-(1999): "Employment relations and industrial welfare in Britain: Business ethics versus labour markets", Business and Economic History, 28, pp. 167-179.

GOURVISH, Terry R. (1973): “A British Business Elite: The Chief Executive Managers of the Railway Industry", Business History Review, XLVIII, 3, pp. 289-316. 
HOWLET, Peter (2000): “Evidence of the Existence of an Internal Labour Market in the Great Eastern Railway Company, 1875-1905", Business History, 42, 1, pp. 21-40.

JEFATURA SUPERIOR DE ESTADÍSTICA (1924): Boletín de Estadística. Segunda Época, Madrid, Imprenta de los Sobrinos de Sucesora de M. Minuesa de los Ríos.

INSTITUTO DE REFORMAS SOCIALES (1923): Movimiento de los precios al pormenor en España durante la Guerra y la posguerra 1914-1922, Madrid, Sobrinos de Sucesora de M. Minuesa.

KINGSFORD, Peter W. (1970): Victorian Railwaymen. The emergence and Growth of Railway Labour 1830-1870, London, Frank Cass.

LLONCH, Montserrat (2004): "Jornadas, salarios y costes laborales en el sector textil catalán (1891-1936)", Revista de Historia Industrial, 26, pp. 101-140.

LUMMIS, Trevor (1994): The Labour Aristocracy, 1851-1914, Aldershot, Scholar Press.

MALUQUER DE MOTES, Jordi (1989): "Precios, salarios y beneficios. La distribución de la renta", en Estadísticas Históricas de España. Siglos XIX y XX, Madrid, Banco Exterior, pp. 495-532.

MARTINEZ VARA, Tomás (2004): “Los costes laborales y la crisis de MZA, 19131935. Datos y algunas reflexiones", Transportes, Servicios y Telecomunicaciones, 7 , pp. 103-146.

-(2005): “Labour cost in a leading Spanish company: MZA Railway Company, 19121935", Journal of Transport History, 26, 2, pp. 60-78.

MZA (1933 y 1935): Ventajas diversas disfrutadas por el personal de los diferentes servicios en el ejercicio de 1933 (mecanografiado), Madrid.

-(1934): Situación del personal en la Compañía M.Z.A. (1913-1933), Madrid, Sucesores de Rivadeneyra.

PLAZA PLAZA, Antonio (2004): El Asociacionismo Ferroviario en España (1870-1917), Tesis Doctoral, Madrid, Universidad Autónoma de Madrid.

RIBEILL, George (1980): Le Personnel des Compagnies de Chemins de fer: matériaux pour une contribution a la sociologie historique de professions, París, Development et Amenagement.

-(1998): "Variations sur les cultures d'entreprise: le cas des compagnies françaises de chemins de fer", en MERGER, Michèle, y BARJOT, Dominique (dirs.), Les entreprises et leurs réseaux: homme, capitaux, techniques et pouvoirs: XIX-XX siècles. Mélanges en l'honneur de François Caron, París, Université Paris Sorbonne.

SANCHO RORA, Agustín (2004): “El mercado de trabajo en una empresa flexible: la Fundición Averly de Zaragoza (1880-1930)", Revista de Historia Económica, XXII, 2, pp. $425-469$.

SAVAGE, Mike (2000): “Discipline, Surveillance and the 'Career': Employment on Great Western Railway 1833-1914", en MCKINLAY, Alan, y STARKEY, Ken (eds.), Foucault, Management and Organization Theory: from Panopticon to Technologies of Self, London, Sage, pp. 65-92. 
SOTO CARMONA, Álvaro (1992): “La evolución salarial en el primer tercio del siglo XX: en busca de una perspectiva comparada. Los Estados Unidos, Francia y España", Historia Social, 13, pp. 53-76.

TEDDE, Pedro (1978): "Las compañías ferroviarias en España (1855-1935)", en ARTOLA, Miguel (dir.), Los ferrocarriles en España, 1844-1943, Madrid, Banco de España, Vol. 2, pp. 9-354.

TORTELLA, Gabriel (1994): El desarrollo de la España contemporánea. Historia económica de los siglos XIX y XX, Madrid, Alianza.

VIDAL OLIVARES, Javier (1996): “Las compañías ferroviarias y la difusión de las modernas formas de gestión empresarial en España, 1950-1914", en COMÍN, Francisco, y MARTÍN ACEÑA, Pablo (eds.), La empresa en la Historia de España, Madrid, Civitas, pp. 285-301.

VILAR RODRÍGUEZ, Margarita (2004): “La ruptura posbélica a través del comportamiento de los salarios industriales: nueva evidencia cuantitativa (1908-1963)", Revista de Historia Industrial, 25, pp. 81-125. 


\section{APÉNDICE 1}

PERSONAL FIJO Y EVENTUAL, Y SALARIOS Y PENSIONES, 1915-1935

(miles de pesetas)

\begin{tabular}{|c|c|c|c|c|c|c|c|}
\hline \multirow{2}{*}{ Año } & \multicolumn{5}{|c|}{ Personal Fijo } & \multicolumn{2}{|c|}{ Personal Eventual $^{\star \star \star}$} \\
\hline & $\begin{array}{c}\text { Empleados } \\
\text { (1) }\end{array}$ & $\begin{array}{c}\text { Pensiones* } \\
\text { (2) }\end{array}$ & $\begin{array}{c}\text { Obvenciones }{ }^{\star *} \\
\text { (3) }\end{array}$ & $\begin{array}{c}\text { Salarios } \\
\text { (4) }\end{array}$ & $\begin{array}{c}\text { Total } \\
(5)=(3)+(4)\end{array}$ & $\begin{array}{c}\text { Empleados } \\
\text { (6) }\end{array}$ & $\begin{array}{c}\text { Salarios } \\
(7)\end{array}$ \\
\hline 1915 & 22.727 & 1.155 & 7.413 & 30.825 & 38.238 & & \\
\hline 1916 & 22.267 & 1.308 & 7.855 & 30.393 & 38.248 & & \\
\hline 1917 & 22.683 & 1.435 & 8.526 & 33.225 & 41.751 & & \\
\hline 1918 & 23.176 & 1.536 & 9.355 & 36.631 & 45.986 & & \\
\hline 1919 & 24.024 & 1.639 & 9.560 & 45.415 & 54.975 & 4.775 & 4.117 \\
\hline 1920 & 25.403 & 1.706 & 13.182 & 65.711 & 78.893 & 6.088 & 6.293 \\
\hline 1921 & 26.947 & 1.818 & 17.030 & 76.249 & 93.279 & 7.551 & 8.146 \\
\hline 1922 & 28.516 & 2.003 & 18.836 & 78.787 & 97.623 & 8.489 & 9.514 \\
\hline 1923 & 27.942 & 2.242 & 20.080 & 80.704 & 100.784 & 8.654 & 8.509 \\
\hline 1924 & 28.054 & 2.586 & 20.355 & 80.551 & 100.906 & 9.956 & 15.905 \\
\hline 1925 & 28.519 & 3.146 & 20.766 & 82.233 & 102.999 & 11.043 & 13.731 \\
\hline 1926 & 30.019 & 3.770 & 21.676 & 87.288 & 108.964 & 7.818 & 10.368 \\
\hline 1927 & 30.154 & 4.204 & 22.804 & 87.917 & 110.721 & 9.081 & 13.007 \\
\hline 1928 & 30.642 & 4.660 & 23.092 & 90.354 & 113.446 & 9.630 & 13.300 \\
\hline 1929 & 31.374 & 5.052 & 23.889 & 93.400 & 117.289 & 8.968 & 14.001 \\
\hline 1930 & 31.820 & 5.557 & 24.123 & 95.051 & 119.174 & 7.018 & 11.248 \\
\hline 1931 & 32.113 & 5.974 & 24.307 & 96.843 & 121.150 & 4.296 & 7.133 \\
\hline 1932 & 33.692 & 6.433 & 23.823 & 96.383 & 120.206 & - & - \\
\hline 1933 & 33.243 & 6.867 & 25.886 & 95.972 & 121.858 & 3.977 & 6.902 \\
\hline 1934 & 33.661 & 7.318 & 25.951 & 96.460 & 122.411 & - & - \\
\hline 1935 & 33.839 & 8.151 & 25.935 & 94.309 & 120.244 & 4.453 & 7.813 \\
\hline
\end{tabular}

* Incluye todo lo percibido por los pensionistas.

** Incluye todas las partidas del Apéndice 2a, menos el economato, las escuelas y los anticipos sin interés, más las del Apéndice $2 b$.

*** "Número medio de eventuales por día" e "Importe de los haberes abonados".

Fuentes: AHF C/53/33: 1915-1921; C/54/34: 1922-1930; C/55/45: 1931-1932; MZA (1933 у 1935). 


\section{APÉNDICE 2a}

INSTITUCIONES DE CARÁCTER BENÉFICO Y DE PREVISIÓN ESTABLECIDAS POR LA COMPAÑÍA, 1915-1935

(pesetas por empleado fijo)

\begin{tabular}{|c|c|c|c|c|c|c|c|c|c|c|}
\hline Año & (1) & (2) & (3) & (4) & (5) & (6) & (7) & (8) & (9) & (10) \\
\hline 1915 & 0,55 & 0,55 & 20,38 & 36,11 & 0,93 & 8,69 & 0,25 & 2,68 & 0,79 & 2,48 \\
\hline 1916 & 0,56 & 0,88 & 22,62 & 37,84 & 0,98 & 9,30 & 0,30 & 2,63 & 0,84 & 2,27 \\
\hline 1917 & 0,55 & 0,50 & 23,74 & 39,46 & 1,11 & 9,39 & 0,07 & 2,75 & 1,13 & 2,55 \\
\hline 1918 & 0,54 & 0,60 & 21,51 & 52,76 & 1,35 & 9,24 & 0,41 & 6,04 & 1,30 & 5,27 \\
\hline 1919 & 0,42 & 0,67 & 27,97 & 52,77 & 1,62 & 8,83 & 0,12 & 4,64 & 1,51 & 2,41 \\
\hline 1920 & 0,35 & 0,83 & 29,83 & 61,98 & 1,89 & 8,55 & 0,13 & 2,77 & 3,05 & 2,61 \\
\hline 1921 & 0,46 & 0,78 & 24,48 & 76,96 & 2,07 & 7,95 & 0,30 & 3,40 & 1,91 & 6,09 \\
\hline 1922 & 0,53 & 0,90 & 24,47 & 72,15 & 1,94 & 7,76 & 0,25 & 3,50 & 2,50 & 6,21 \\
\hline 1923 & 0,54 & 1,05 & 17,17 & 78,23 & 2,11 & 8,17 & 0,16 & 7,72 & 2,05 & 6,20 \\
\hline 1924 & 0,53 & 1,29 & 17,38 & 77,94 & 2,24 & 8,35 & 0,26 & 5,62 & 2,79 & 5,90 \\
\hline 1925 & 0,53 & 1,60 & 22,59 & 71,12 & 2,57 & 8,43 & 0,49 & 7,48 & 2,20 & 9,48 \\
\hline 1926 & 0,50 & 1,52 & 19,72 & 67,66 & 2,29 & 8,10 & 0,42 & 5,21 & 2,46 & 8,33 \\
\hline 1927 & 0,50 & 1,49 & 20,00 & 69,29 & 2,67 & 8,29 & 0,51 & 5,80 & 2,32 & 8,28 \\
\hline 1928 & 0,49 & 1,50 & 19,80 & 70,60 & 3,10 & 8,46 & 0,37 & 5,43 & 2,57 & 2,69 \\
\hline 1929 & 0,48 & 1,33 & 18,90 & 73,96 & 3,22 & 8,51 & 0,86 & 5,86 & 3,18 & 2,69 \\
\hline 1930 & 0,47 & 1,72 & 19,89 & 67,97 & 3,17 & 8,94 & 0,85 & 5,03 & 2,75 & 2,95 \\
\hline 1931 & 0,47 & 1,21 & 20,62 & 85,72 & 3,28 & 8,62 & 0,97 & 8,04 & 2,47 & 3,28 \\
\hline 1932 & 0,45 & 1,58 & 16,56 & 81,83 & 2,92 & 8,62 & 1,05 & 4,41 & 2,50 & 3,58 \\
\hline 1933 & 0,45 & 1,44 & 18,75 & 99,45 & 3,32 & 9,12 & 0,77 & 4,38 & 2,26 & 4,65 \\
\hline 1934 & 0,45 & 1,73 & 25,30 & 92,80 & 3,13 & 9,22 & 0,86 & 4,57 & 1,98 & 4,75 \\
\hline 1935 & 0,44 & 1,76 & 26,06 & 92,68 & 3,17 & 9,18 & 0,41 & 6,43 & 1,71 & 4,33 \\
\hline
\end{tabular}
(1) Intereses por anticipos gratuitos.
(2) Gastos de medicinas y botica.
(3) Economato.
(4) Abono de haberes en caso de enfermedades comunes.
(5) Escuelas (incluye haberes de los profesores, importe del material, billetes gratuitos y otros gastos).
(6) Gratificaciones a los agentes de poco sueldo y familia numerosa con más de tres hijos menores de 17 años.
(7) Médicos ajenos a la compañía.
(8) Socorros (normalmente por el fallecimiento de algún agente sin derecho a pensión).
(9) Vestuario.
(10) Abono de haberes en casos de accidentes de trabajo, siempre que no pueda imputarse a imprudencia.
Fuentes: AHF C/53/33: 1915-1921; C/54/34: 1922-1930; C/55/45: 1931-1932; MZA (1933 у 1935). 


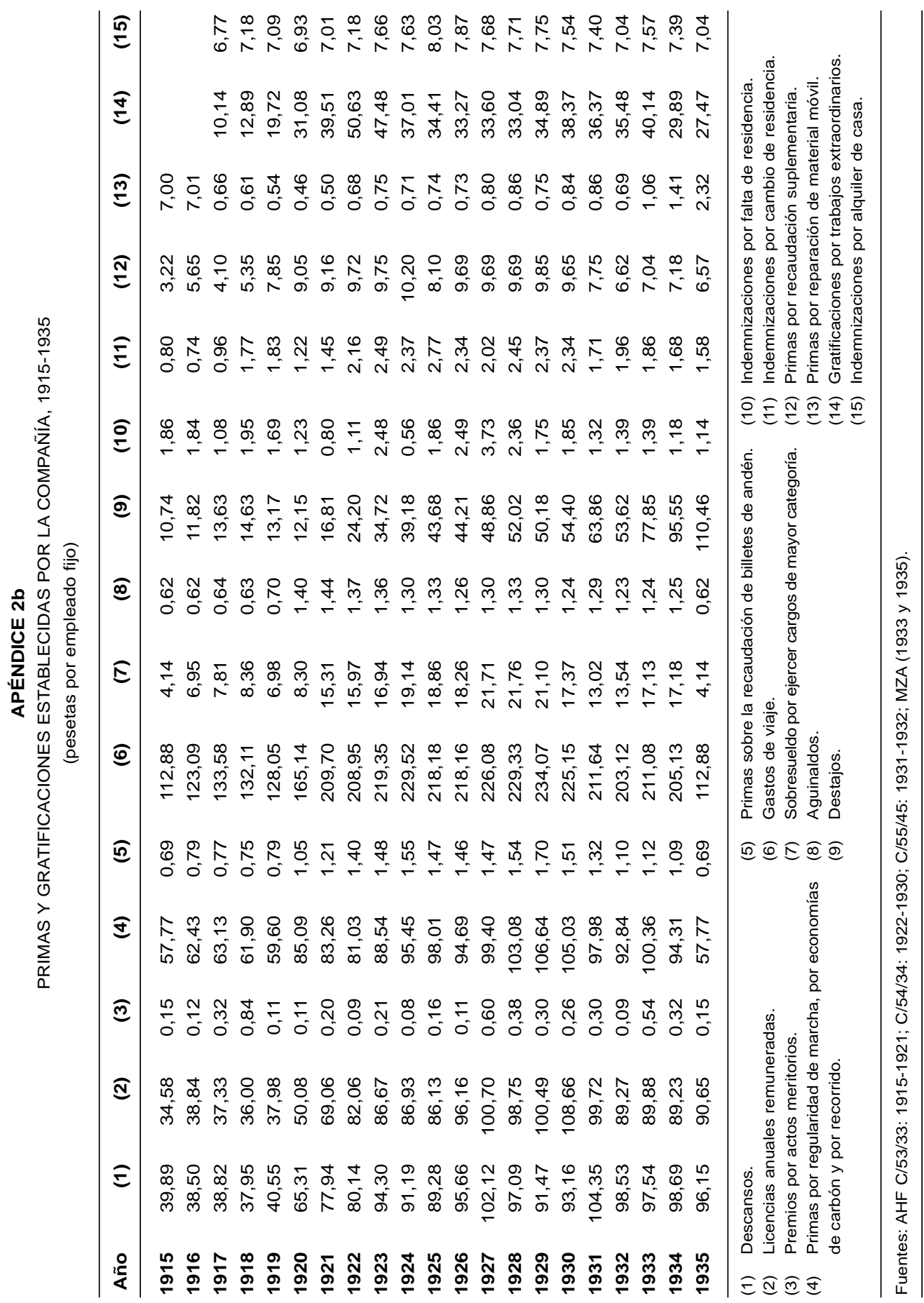




\section{APÉNDICE 2C}

PRESTACIONES QUE NO SUPONEN INCREMENTOS MONETARIOS

A LOS EMPLEADOS DE LA COMPAÑÍA, 1915-1935

(pesetas por empleado fijo)

\begin{tabular}{lcccc}
\hline Año & Billetes gratuitos & Dormitorios & Viviendas & Total \\
\hline $\mathbf{1 9 1 5}$ & 278,47 & 5,78 & 23,49 & 307,73 \\
$\mathbf{1 9 1 6}$ & 316,02 & 6,38 & 30,19 & 352,62 \\
$\mathbf{1 9 1 7}$ & 330,11 & 6,56 & 29,72 & 366,44 \\
$\mathbf{1 9 1 8}$ & 329,99 & 7,52 & 31,30 & 368,82 \\
$\mathbf{1 9 1 9}$ & 331,95 & 7,61 & 30,82 & 370,42 \\
$\mathbf{1 9 2 0}$ & 406,33 & 7,92 & 29,28 & 443,53 \\
$\mathbf{1 9 2 1}$ & 407,31 & 8,92 & 27,93 & 444,16 \\
$\mathbf{1 9 2 2}$ & 445,08 & 12,78 & 26,74 & 484,61 \\
$\mathbf{1 9 2 3}$ & 123,82 & 14,51 & 27,37 & 165,73 \\
$\mathbf{1 9 2 4}$ & 135,95 & 14,48 & 27,59 & 178,01 \\
$\mathbf{1 9 2 5}$ & 144,64 & 13,17 & 27,85 & 185,66 \\
$\mathbf{1 9 2 6}$ & 142,97 & 14,79 & 26,62 & 184,41 \\
$\mathbf{1 9 2 7}$ & 150,46 & 13,87 & 26,90 & 191,21 \\
$\mathbf{1 9 2 8}$ & 165,85 & 13,68 & 26,48 & 206,02 \\
$\mathbf{1 9 2 9}$ & 220,88 & 15,21 & 26,53 & 262,61 \\
$\mathbf{1 9 3 0}$ & 214,39 & 15,62 & 26,49 & 256,50 \\
$\mathbf{1 9 3 1}$ & 219,91 & 17,17 & 26,25 & 263,32 \\
$\mathbf{1 9 3 2}$ & 240,11 & 16,51 & 25,21 & 281,84 \\
$\mathbf{1 9 3 3}$ & 246,84 & 17,74 & 28,87 & 327,53 \\
$\mathbf{1 9 3 4}$ & 282,04 & 17,30 & & \\
$\mathbf{1 9 3 5}$ & 291,85 & 16,72 & & \\
\hline & & & & \\
& & & & \\
\hline
\end{tabular}

Fuentes: AHF, C/53/33: 1915-1921; C/54/34: 1922-1930; C/55/45: 1931-1932; MZA (1933 y 1935). 


\section{APÉNDICE 3a}

SALARIOS DE LOS EMPLEADOS DE MZA DE LA RED ANTIGUA, 1915-1934

(números índice, base $100=1915$ )

\begin{tabular}{|c|c|c|c|c|c|c|c|}
\hline \multirow{2}{*}{ Año } & \multicolumn{2}{|c|}{ Secretaría General } & \multicolumn{2}{|c|}{ Dirección General } & \multicolumn{3}{|c|}{ Sanitario } \\
\hline & (1) & $(2)$ & (3) & (4) & (5) & (6) & $(7)$ \\
\hline 1915 & 100,00 & 100,00 & 100,00 & 100,00 & 100,00 & 100,00 & 100,00 \\
\hline $1916^{*}$ & 100,74 & 104,17 & 108,25 & 106,31 & 100,00 & 108,20 & 109,95 \\
\hline 1917 & 108,34 & 108,33 & 109,88 & 108,44 & 107,24 & 109,88 & 120,17 \\
\hline 1918 & 126,04 & 103,75 & 109,51 & 109,69 & 109,63 & 109,51 & 117,23 \\
\hline $1919^{*}$ & 175,64 & 114,90 & 117,22 & 121,20 & 118,23 & 117,22 & 123,91 \\
\hline 1920 & 176,09 & 133,71 & 126,48 & 142,40 & 164,15 & 126,48 & 162,73 \\
\hline 1921 & 165,77 & 213,86 & 178,02 & 206,69 & 281,58 & 178,02 & 284,30 \\
\hline 1922 & 143,28 & 218,44 & 177,18 & 219,19 & 282,38 & 177,18 & 291,32 \\
\hline 1923 & 146,69 & 213,75 & 174,20 & 211,38 & 284,53 & 174,20 & 298,00 \\
\hline 1924 & 146,69 & 221,47 & 176,14 & 216,63 & 284,22 & 176,14 & 317,50 \\
\hline 1925 & 154,61 & 213,75 & 177,63 & 220,51 & 287,53 & 177,63 & 341,02 \\
\hline 1926 & 158,76 & 218,44 & 179,65 & 221,70 & 272,62 & 179,65 & 360,19 \\
\hline 1927 & 164,38 & 175,19 & 185,78 & 210,31 & 277,59 & 185,78 & 358,78 \\
\hline 1928 & 167,94 & 181,08 & 188,08 & 213,19 & 289,74 & 188,08 & 364,80 \\
\hline 1929 & 168,41 & 183,01 & 191,53 & 220,57 & 283,54 & 191,53 & 373,88 \\
\hline 1930 & 145,47 & 183,01 & 196,36 & 232,02 & 279,98 & 196,36 & 379,89 \\
\hline 1931 & 143,14 & 191,14 & 199,06 & 226,08 & 279,98 & 199,06 & 388,91 \\
\hline 1932 & 151,57 & 201,09 & 202,29 & 227,39 & 274,89 & 202,29 & 402,94 \\
\hline 1933 & 142,91 & 195,25 & 203,43 & 230,71 & 282,01 & 203,43 & 350,10 \\
\hline 1934 & 151,57 & 201,09 & 184,91 & 235,02 & 256,84 & 184,91 & 100,00 \\
\hline
\end{tabular}

* Reconstrucción sobre la misma documentación de los Presupuestos.
(1) Secretaría General.
(2) Personal de oficinas.
(3) Ordenanzas, porteros y conserjes.
(4) Personal de oficinas.
(5) Médicos.
(6) Practicantes.
(7) Auxiliares.

Fuentes: AHF, Presupuestos, Libros 45-195. 


\section{APÉNDICE 3b}

SALARIOS DE LOS EMPLEADOS DE MZA DE LA RED ANTIGUA, 1915-1934

(números índice, base 100=1915)

\begin{tabular}{|c|c|c|c|c|c|c|c|c|c|}
\hline \multirow{2}{*}{ Año } & \multicolumn{3}{|c|}{ Contabilidad } & \multicolumn{4}{|c|}{ Intervención y Estadística } & \multicolumn{2}{|c|}{ Contencioso } \\
\hline & (1) & (2) & (3) & (4) & (5) & (6) & (7) & (8) & (9) \\
\hline 915 & 100,00 & 100,00 & 100,00 & 100,00 & 100,00 & 100,00 & 100,00 & 100,00 & 100,00 \\
\hline 916* & 104,85 & 100,71 & 104,81 & 100,00 & 102,25 & 100,00 & 100,00 & 100,00 & 107,97 \\
\hline 1917 & 119,75 & 107,24 & 119,75 & 105,71 & 117,08 & 107,24 & 102,22 & 100,02 & 108,29 \\
\hline 918 & 121,04 & 110,82 & 121,04 & 114,12 & 118,71 & 109,64 & 103,46 & 99,13 & 108,86 \\
\hline $1919^{\star}$ & 120,37 & 122,72 & 120,37 & 114,12 & 137,42 & 118,23 & 103,29 & 100,72 & 102,09 \\
\hline 1920 & 114,75 & 146,18 & 114,75 & 130,98 & 164,52 & 164,15 & 161,19 & 112,86 & 125,43 \\
\hline 1921 & 177,34 & 200,82 & 177,34 & 157,46 & 262,63 & 281,58 & 295,47 & 148,17 & 206,45 \\
\hline 1922 & 177,37 & 198,43 & 177,37 & 228,90 & 262,78 & 282,38 & 284,19 & 172,02 & 195,64 \\
\hline 1923 & 183,57 & 206,01 & 183,58 & 231,16 & 268,87 & 284,53 & 278,42 & 167,05 & 201,96 \\
\hline 1924 & 185,97 & 210,44 & 185,97 & 232,92 & 271,63 & 284,22 & 267,41 & 174,54 & 198,48 \\
\hline 1925 & 199,54 & 228,12 & 199,54 & 243,20 & 276,58 & 287,54 & 275,84 & 181,80 & 204,43 \\
\hline 1926 & 182,20 & 221,71 & 182,21 & 237,86 & 275,15 & 272,62 & 278,42 & 170,96 & 204,43 \\
\hline 1927 & 177,37 & 224,88 & 177,37 & 246,67 & 274,28 & 277,59 & 277,53 & 177,73 & 211,26 \\
\hline 1928 & 194,75 & 223,50 & 194,76 & 240,23 & 274,95 & 289,75 & 282,86 & 190,20 & 214,67 \\
\hline 1929 & 198,89 & 228,31 & 198,90 & 236,47 & 275,72 & 283,55 & 269,89 & 192,88 & 218,34 \\
\hline 1930 & 200,61 & 233,12 & 200,62 & 242,61 & 278,27 & 279,99 & 261,28 & 195,75 & 207,34 \\
\hline 1931 & 200,61 & 233,12 & 200,62 & 240,93 & 278,27 & 279,99 & 261,28 & 204,94 & 207,34 \\
\hline 1932 & 181,48 & 239,76 & 181,48 & 240,93 & 279,45 & 274,89 & 292,90 & 209,29 & 198,48 \\
\hline 1933 & 182,15 & 229,77 & 182,16 & 240,75 & 284,00 & 282,01 & 289,25 & 208,37 & 216,64 \\
\hline 1934 & & 241,33 & & 233,69 & 287,07 & 256,84 & 278,24 & 220,04 & 216,70 \\
\hline
\end{tabular}

* Reconstrucción sobre la misma documentación de los Presupuestos.
(1) Pagadores.
(2) Oficinas y caja.
(3) Ordenanzas.
(4) Revisores.
(5) Oficinas.
(6) Ordenanzas.
(7) Mozos.
(8) Oficinas.
(9) Ordenanzas.

Fuentes: AHF, Presupuestos, Libros 45-195. 
APÉNDICE 3C

SALARIOS DE LOS EMPLEADOS DE MZA DE LA RED ANTIGUA, 1915-1932

(números índice, base 100=1915)

\begin{tabular}{|c|c|c|c|c|c|c|c|c|c|}
\hline \multirow{2}{*}{ Año } & \multicolumn{9}{|c|}{ Movimiento } \\
\hline & (1) & (2) & (3) & (4) & (5) & (6) & (7) & (8) & (9) \\
\hline 1915 & 100,00 & 100,00 & 100,00 & 100,00 & 100,00 & 100,00 & 100,00 & 100,00 & 100,00 \\
\hline $1916^{*}$ & 100,53 & 100,22 & 100,82 & 100,50 & 105,97 & 84,05 & 100,78 & 99,80 & 100,65 \\
\hline 1917 & 105,76 & 103,88 & 106,29 & 104,51 & 114,53 & 88,08 & 103,79 & 105,27 & 106,18 \\
\hline 1918 & 110,99 & 107,59 & 111,83 & 108,57 & 122,56 & 92,10 & 106,80 & 110,75 & 108,62 \\
\hline $1919^{\star}$ & 119,76 & 115,39 & 118,13 & 114,13 & 128,96 & 101,56 & 113,54 & 121,91 & 118,54 \\
\hline 1920 & 139,61 & 133,10 & 142,54 & 132,55 & 142,81 & 147,84 & 133,75 & 110,85 & 140,57 \\
\hline 1921 & 223,79 & 214,09 & 236,66 & 216,58 & 226,86 & 233,38 & 219,56 & 229,31 & 164,15 \\
\hline 1922 & 216,70 & 214,44 & 241,79 & 219,14 & 225,70 & 229,28 & 219,36 & 246,86 & 239,43 \\
\hline 1923 & 217,59 & 216,81 & 242,75 & 220,76 & 224,37 & 227,12 & 219,42 & 246,45 & 240,89 \\
\hline 1924 & 218,43 & 216,81 & 243,43 & 219,37 & 222,56 & 232,79 & 207,72 & 247,87 & 242,60 \\
\hline 1925 & 218,34 & 216,72 & 243,09 & 219,37 & 226,46 & 241,80 & 207,78 & 235,40 & 243,33 \\
\hline 1926 & 226,14 & 216,68 & 239,60 & 221,31 & 211,35 & 233,76 & 260,10 & 235,90 & 239,92 \\
\hline 1927 & 219,41 & 216,12 & 241,79 & 221,04 & 208,03 & 240,39 & 260,10 & 234,69 & 238,94 \\
\hline 1928 & 227,74 & 212,59 & 237,48 & 219,09 & 211,86 & 240,39 & 201,70 & 234,79 & 239,59 \\
\hline 1929 & 227,74 & 212,59 & 237,48 & 219,09 & 211,86 & 240,39 & 201,70 & 234,79 & 239,59 \\
\hline 1930 & 228,18 & 211,25 & 234,61 & 218,98 & 215,47 & 233,31 & 204,25 & 234,28 & 237,48 \\
\hline 1931 & 229,11 & 210,34 & 239,47 & 219,59 & 216,67 & 234,43 & 204,64 & 236,21 & 237,72 \\
\hline 1932 & 229,15 & 210,34 & 240,42 & 219,59 & 219,20 & 243,59 & 213,21 & 249,90 & 245,77 \\
\hline
\end{tabular}

* Reconstrucción sobre la misma documentación de los Presupuestos.

(1) Jefes de estación.

(2) Conductores.

(3) Factores de telégrafos.

(4) Guardafrenos.

(5) Oficinas.

(6) Ordenanzas.

(7) Mozos de tren.

(8) Personal inferior de las estaciones.

(9) Pequeño material.

Fuentes: AHF, Presupuestos, Libros 45-195. 


\section{APÉNDICE 3d}

SALARIOS DE LOS EMPLEADOS DE MZA DE LA RED ANTIGUA, 1915-1934

(números índice, base 100=1915)

\begin{tabular}{|c|c|c|c|c|c|c|c|c|}
\hline \multirow{2}{*}{ Año } & \multicolumn{8}{|c|}{ Vía y Obras } \\
\hline & (1) & (2) & (3) & (4) & (5) & (6) & (7) & (8) \\
\hline 1915 & 100,00 & 100,00 & 100,00 & 100,00 & 100,00 & 100,00 & 100,00 & 100,00 \\
\hline $1916^{*}$ & 99,58 & 104,82 & 110,82 & 97,98 & 99,88 & 100,11 & 101,58 & 104,49 \\
\hline 1917 & 94,44 & 105,15 & 115,61 & 101,40 & 105,38 & 108,03 & 100,53 & 103,21 \\
\hline 1918 & 91,86 & 104,55 & 112,89 & 109,69 & 106,80 & 108,03 & 107,89 & 116,21 \\
\hline $1919^{*}$ & 92,04 & 106,09 & 116,58 & 116,28 & 112,43 & 109,25 & 113,16 & 128,41 \\
\hline 1920 & 117,77 & 135,22 & 140,67 & 150,16 & 139,29 & 142,59 & 152,11 & 157,46 \\
\hline 1921 & 184,74 & 184,12 & 151,68 & 246,82 & 199,17 & 230,10 & 233,16 & 242,54 \\
\hline 1922 & 187,19 & 186,48 & 159,84 & 249,69 & 200,06 & 230,21 & 235,26 & 242,86 \\
\hline 1923 & 188,78 & 187,21 & 229,60 & 249,53 & 201,30 & 230,32 & 233,16 & 242,54 \\
\hline 1924 & 188,21 & 188,66 & 227,07 & 245,74 & 204,38 & 230,32 & 233,16 & 242,70 \\
\hline 1925 & 193,03 & 198,51 & 233,35 & 246,82 & 205,50 & 230,66 & 233,16 & 243,18 \\
\hline 1926 & 181,88 & 201,33 & 233,35 & 251,47 & 200,59 & 231,22 & 233,68 & 243,18 \\
\hline 1927 & 180,67 & 211,15 & 238,28 & 248,14 & 204,56 & 230,77 & 233,68 & 243,18 \\
\hline 1928 & 178,27 & 214,94 & 246,18 & 239,61 & 205,74 & 230,43 & 233,16 & 242,86 \\
\hline 1929 & 184,21 & 220,52 & 252,98 & 244,88 & 210,65 & 229,77 & 232,11 & 243,82 \\
\hline 1930 & 186,37 & 216,91 & 272,34 & 229,61 & 213,55 & 228,32 & 232,11 & 243,82 \\
\hline 1931 & 182,94 & 218,40 & 279,73 & 269,22 & 214,67 & 227,65 & 232,11 & 243,82 \\
\hline 1932 & 180,64 & 209,49 & 272,73 & 261,01 & 214,62 & 249,72 & 237,37 & 298,39 \\
\hline 1933 & 189,49 & 222,22 & 284,91 & 239,07 & 222,13 & 262,21 & 278,42 & 346,07 \\
\hline 1934 & 189,88 & 233,53 & 283,87 & 293,41 & 229,53 & 262,10 & 278,42 & 346,23 \\
\hline
\end{tabular}

* Reconstrucción sobre misma documentación de los Presupuestos.
(1) Personal superior de los Servicios.
(2) Oficinas.
(3) Ordenanzas.
(4) Almacenes.
(5) Talleres.
(6) Conservación de la vía.
(7) Vigilancia de la vía (varones).
(8) Vigilancia de la vía (guardesas).

Fuentes: AHF, Presupuestos, Libros 45-195. 


\section{APÉNDICE 4}

SALARIOS DE LOS EMPLEADOS DE MZA DE LAS DOS REDES, 1915-1934

(números índice, base 100=1915)

\begin{tabular}{|c|c|c|c|c|c|c|c|c|c|}
\hline \multirow{2}{*}{ Año } & \multicolumn{9}{|c|}{ Material y Tracción } \\
\hline & (1) & (2) & (3) & (4) & (5) & (6) & (7) & (8) & (9) \\
\hline 1915 & 100,00 & 100,00 & 100,00 & 100,00 & 100,00 & 100,00 & 100,00 & $100 ., 00$ & 100,00 \\
\hline 1916 & 102,77 & 104,82 & 94,07 & 100,00 & 104,76 & 104,23 & 106,76 & 105,08 & 105,61 \\
\hline 1917 & 103,64 & 96,22 & 86,07 & 99,30 & 111,36 & 104,23 & 113,70 & 110,17 & 111,23 \\
\hline 1918 & 103,75 & 100,22 & 88,42 & 99,94 & 112,76 & 115,69 & 118,27 & 110,33 & 112,79 \\
\hline 1919 & 110,48 & 114,27 & 91,72 & 102,54 & 115,23 & 115,81 & 118,44 & 117,12 & 117,25 \\
\hline 1920 & 130,72 & 139,67 & 115,89 & 114,54 & 140,31 & 174,58 & 154,39 & 159,04 & 147,15 \\
\hline 1921 & 200,05 & 209,09 & 184,27 & 161,63 & 206,88 & 282,92 & 256,93 & 246,04 & 242,93 \\
\hline 1922 & 194,91 & 214,44 & 182,07 & 179,77 & 224,05 & 289,46 & 249,15 & 259,69 & 246,07 \\
\hline 1923 & 206,73 & 213,84 & 184,66 & 182,68 & 222,22 & 288,94 & 283,16 & 268,98 & 269,61 \\
\hline 1924 & 201,43 & 214,74 & 193,79 & 173,27 & 222,11 & 295,14 & 267,59 & 266,55 & $259 ., 53$ \\
\hline 1925 & 205,90 & 217,11 & 187,30 & 178,90 & 234,80 & 305,10 & 267,76 & 270,92 & 260,61 \\
\hline 1926 & 207,81 & 219,27 & 179,72 & 175,51 & 231,47 & 311,93 & 270,47 & 273,66 & 256,64 \\
\hline 1927 & 204,11 & 217,59 & 178,31 & 171,62 & 234,72 & 318,93 & 267,34 & 271,80 & 257,55 \\
\hline 1928 & 199,58 & 217,24 & 180,15 & 171,79 & 243,47 & 329,47 & 283,07 & 256,94 & 257,22 \\
\hline 1929 & 195,27 & 223,28 & 178,88 & 173,16 & 246,49 & 341,57 & 279,35 & 284,08 & 256,64 \\
\hline 1930 & 197,58 & 220,91 & 180,00 & 173,22 & 256,05 & 338,91 & 281,81 & 287,31 & 259,37 \\
\hline 1931 & 200,71 & 220,61 & 182,50 & 174,39 & 251,62 & 338,91 & 281,13 & 283,11 & 259,53 \\
\hline 1932 & 201,07 & 222,85 & 184,33 & 172,91 & 251,20 & 327,16 & 278,34 & 292,40 & 261,60 \\
\hline 1933 & 201,28 & 223,24 & 182,78 & 172,66 & 256,37 & 323,34 & 273,60 & 312,92 & 263,00 \\
\hline 1934 & 201,79 & 219,40 & 182,36 & 174,31 & 257,88 & 330,92 & 281,97 & 308,15 & 264,40 \\
\hline
\end{tabular}

${ }^{*}$ Reconstrucción sobre la misma documentación de los Presupuestos.
(1) Personal directivo y administrativo.
(2) Personal directivo y administrativo a jornal de los talleres generales.
(3) Personal directivo y administrativo de la División de Material Móvil.
(4) Maquinistas y fogoneros.
(5) Oficinas centrales y regionales.
(6) Ordenanzas.
(7) Depósitos.
(8) Obreros de los talleres.
(9) Obreros de los recorridos. 


\section{APÉNDICE 5a}

SALARIOS DE LOS EMPLEADOS DE MZA DE LA RED CATALANA, 1915-1932

(números índice, base 100=1915)

\begin{tabular}{|c|c|c|c|c|c|c|c|c|}
\hline \multirow{2}{*}{ Año } & \multicolumn{4}{|c|}{ Intervención y Estadística } & \multicolumn{4}{|c|}{ Movimiento } \\
\hline & (1) & $(2)$ & (3) & (4) & (5) & (6) & (7) & (8) \\
\hline 1915 & 100,00 & 100,00 & 100,00 & 100,00 & 100,00 & 100,00 & 100,00 & 100,00 \\
\hline $1916^{\star}$ & 103,18 & 104,95 & 103,61 & 99,92 & 104,83 & 101,61 & 100,00 & 91,88 \\
\hline 1917 & 110,38 & 109,51 & 106,33 & 119,71 & 114,36 & 111,06 & 109,61 & 92,73 \\
\hline 1918 & 146,25 & 109,27 & 106,79 & 144,26 & 115,07 & 111,59 & 119,68 & 93,49 \\
\hline 1919* & 219,91 & 125,61 & 118,16 & 271,14 & 143,81 & 138,69 & 127,72 & 107,19 \\
\hline 1920 & 245,86 & 147,46 & 128,61 & 288,99 & 152,27 & 144,73 & 144,92 & 122,20 \\
\hline 1921 & 251,07 & 240,35 & 188,82 & 292,74 & 245,99 & 225,09 & 234,73 & 190,13 \\
\hline 1922 & 259,20 & 241,34 & 190,71 & 301,05 & 247,00 & 226,24 & 234,43 & 192,03 \\
\hline 1923 & 261,03 & 245,27 & 189,29 & 301,05 & 246,94 & 226,24 & 234,41 & 192,03 \\
\hline 1924 & 262,90 & 245,93 & 191,68 & 309,51 & 225,07 & 225,21 & 268,04 & 188,66 \\
\hline $1925^{\star}$ & 261,21 & 243,94 & 196,41 & 287,84 & 226,85 & 223,63 & 265,96 & 200,29 \\
\hline 1926 & 265,76 & 248,58 & 180,85 & 320,99 & 233,04 & 226,88 & 266,69 & 197,25 \\
\hline 1927 & 272,38 & 253,33 & 194,77 & 297,21 & 232,75 & 228,09 & 267,39 & 193,72 \\
\hline 1928 & 266,32 & 254,82 & 194,84 & 300,29 & 235,13 & 231,26 & 269,10 & 194,04 \\
\hline 1929 & 272,57 & 256,09 & 195,13 & 319,61 & 237,20 & 231,40 & 271,21 & 197,25 \\
\hline 1930 & 276,52 & 266,06 & 190,61 & 316,07 & 240,04 & 232,63 & 271,84 & 196,80 \\
\hline 1931 & 274,90 & 265,99 & 193,17 & 310,71 & 241,96 & 234,54 & 268,97 & 197,19 \\
\hline 1932 & & 265,62 & 194,63 & & 245,59 & 235,12 & 272,12 & 204,05 \\
\hline
\end{tabular}

* Reconstrucción sobre la misma documentación de los Presupuestos.
(1) Revisores.
(2) Oficinas.
(3) Ordenanzas.
(4) Mozos.
(5) Factores.
(6) Jefes de estación.
(7) Pequeño material.
(8) Personal subalterno. 


\section{APÉNDICE 5b}

SALARIOS DE LOS EMPLEADOS DE MZA DE LA RED CATALANA, 1915-1932

(números índice, base 100=1915)

Año

\section{Vías y obras}

(1)

(2)

(3)

(4)

(5)

(6)

(7)

\begin{tabular}{llllllll}
\hline $\mathbf{1 9 1 5}$ & 100,00 & 100,00 & 100,00 & 100,00 & 100,00 & 100,00 & 100,00 \\
$\mathbf{1 9 1 6}$ & 101,61 & 108,46 & 100,55 & 106,96 & 103,61 & 107,95 & 100,27 \\
$\mathbf{1 9 1 7}$ & 111,06 & 107,26 & 100,58 & 111,10 & 106,33 & 153,82 & 100,81 \\
$\mathbf{1 9 1 8}$ & 111,60 & 107,90 & 103,91 & 111,39 & 106,79 & 154,75 & 100,13 \\
$\mathbf{1 9 1 9}$ & 138,69 & 115,53 & 113,38 & 122,34 & 118,16 & 168,79 & 115,05 \\
$\mathbf{1 9 2 0}$ & 144,74 & 142,60 & 138,63 & 142,44 & 128,61 & 173,63 & 156,15 \\
$\mathbf{1 9 2 1}$ & 225,09 & 232,67 & 232,89 & 229,56 & 188,82 & 330,42 & 217,81 \\
$\mathbf{1 9 2 2}$ & 226,24 & 232,95 & 192,71 & 237,91 & 190,71 & 331,35 & 218,05 \\
$\mathbf{1 9 2 3}$ & 225,66 & 232,35 & 250,03 & 237,91 & 189,29 & 331,35 & 195,58 \\
$\mathbf{1 9 2 4}$ & 225,22 & 232,33 & 188,69 & 244,84 & 191,68 & 331,35 & 218,08 \\
$\mathbf{1 9 2 5}$ & 223,63 & 232,74 & 210,18 & 238,42 & 196,41 & 331,04 & 218,12 \\
$\mathbf{1 9 2 6}$ & 226,88 & 232,65 & 174,40 & 238,46 & 180,85 & 337,75 & 220,88 \\
$\mathbf{1 9 2 7}$ & 228,09 & 233,32 & 177,40 & 244,84 & 194,77 & 338,68 & 221,08 \\
$\mathbf{1 9 2 8}$ & 231,27 & 233,46 & 183,49 & 253,81 & 194,84 & 351,32 & 222,22 \\
$\mathbf{1 9 2 9}$ & 231,41 & 233,89 & 189,73 & 253,81 & 195,13 & 357,25 & 240,70 \\
$\mathbf{1 9 3 0}$ & 232,63 & 233,88 & 196,24 & 260,20 & 190,61 & 357,56 & 239,63 \\
$\mathbf{1 9 3 1}$ & 234,55 & 234,28 & 188,56 & 260,19 & 193,17 & 333,07 & 227,60 \\
$\mathbf{1 9 3 2}$ & 235,12 & 244,39 & 191,47 & 260,43 & 194,63 & 368,01 & 227,57 \\
\hline & & & & & & & \\
\hline
\end{tabular}

* Reconstrucción sobre la misma documentación de los Presupuestos.
(1) Almacenes.
(2) Brigadas.
(3) Oficinas.
(4) Ordenanzas.
(5) Personal superior.
(6) Vigilancia de las vías (varones).
(7) Vigilancia de las vías (guardesas). 